\title{
Testing hypothesis of skeletal unity using bone histology: The case of the sauropod remains from the Howe-Stephens and Howe Scott quarries (Morrison Formation, Wyoming, USA)
}

\author{
Kayleigh Wiersma-Weyand, Aurore Canoville, \\ Hans-Jakob Siber, and P. Martin Sander
}

\begin{abstract}
Specimens of sauropod dinosaurs from the Upper Jurassic Morrison Formation of the Western Interior of the USA are mostly found as partial and partially articulated skeletons or as isolated bones, as seen in, e.g., the Dinosaur National Monument quarry. This mode of preservation sometimes makes an assignment of specific bones to individuals difficult, especially if other partial skeletons or scattered bones of the same taxon are found nearby. In this study, a detailed assessment of skeletal unity is provided by means of paleohistology for several sauropod partial skeletons and isolated long bones from the Howe-Stephens and the Howe Scott quarries, Wyoming, USA. Using histological characters such as histological ontogenetic stages, cyclicity of growth marks, and remodeling rate, an assignment of bones to individuals was made and compared with previous hypotheses of skeletal unity that were based on field observations only. Our study indicates, based on these characters, it is possible to assign isolated bones to an existing individual, recognize isolated bones as belonging to a new individual, and test whether a specific bone belongs to the assigned individual. The histological evidence should be combined with other sources of data such as morphology and taphonomy to reassess previous hypotheses of skeletal unit. The method presented in this study can be used not only for Morrison Formation sauropods, but to test skeletal unity for other fossil tetrapod taxa as well.
\end{abstract}

Kayleigh Wiersma-Weyand. Abteilung Paläontologie, Institut für Geowissenschaften, Universität Bonn, Nussallee 8, 53115 Bonn, Germany. kayleigh.wiersma@uni-bonn.de

Aurore Canoville. Paleontology, North Carolina Museum of Natural Sciences / Department of Biological Sciences, North Carolina State University, 11 W Jones Street, 27601 Raleigh, North Carolina, USA, and Abteilung Paläontologie, Institut für Geowissenschaften, Universität Bonn, Nussallee 8, 53115 Bonn, Germany. canoville.aurore08@gmail.com

Hans-Jakob Siber. Sauriermuseum Aathal, Zürichstrasse 69, 8607 Aathal, Switzerland. aathal@sibersiber.ch

P. Martin Sander. Abteilung Paläontologie, Institut für Geowissenschaften, Universität Bonn, Nussallee 8, 53115 Bonn, Germany. martin.sander@uni-bonn.de

Wiersma-Weyand, Kayleigh, Canoville, Aurore, Siber, Hans-Jakob, and Sander, P. Martin. 2021. Testing hypothesis of skeletal unity using bone histology: The case of the sauropod remains from the Howe-Stephens and Howe Scott quarries (Morrison Formation, Wyoming, USA). Palaeontologia Electronica, 24(1):a10. https://doi.org/10.26879/766

palaeo-electronica.org/content/2021/3263-bone-histology-sauropods

Copyright: March 2021 Society of Vertebrate Paleontology.

This is an open access article distributed under the terms of the Creative Commons Attribution License,

which permits unrestricted use, distribution, and reproduction in any medium, provided the original author and source are credited. creativecommons.org/licenses/by/4.0 
Keywords: Bone microstructure; intra-specific variability; Upper Jurassic; Diplodocidae; Macronaria

\section{INTRODUCTION}

Sauropod dinosaurs were the largest terrestrial vertebrates that ever walked the Earth. Diverse studies have investigated their morphology, phylogeny, and biology (e.g., Curry Rogers and Wilson, 2005; Klein et al., 2011; Sander et al., 2011a; Sander, 2013 and references therein). Following the works of Armand de Ricqlès and colleagues (1968a, 1968b, 1980; de Ricqlés et al., 1991; Francillon-Vieillot et al., 1990), the long bone histology of sauropod dinosaurs has been well studied and provides information about aspects of their palaeobiology (e.g., Curry, 1999; Sander, 1999, 2000; Sander et al., 2004, 2006; Klein and Sander, 2008; Lehman and Woodward, 2008; Klein et al., 2009, 2012; Woodward and Lehman, 2009; Stein et al., 2010; Sander et al., 2011b and references therein).

Palaeohistological studies on sauropods (e.g., Klein and Sander, 2008; Sander et al., 2011b) were often based on specimens from the Upper Jurassic Morrison Formation, which is well known for its sauropod remains (e.g., Barrett and Upchurch, 2005; Mannion et al., 2013; Tschopp et al., 2015; Carballido et al., 2020). Sauropod remains in the Morrison Formation are primarily found as partial and partially articulated skeletons and as isolated bones, with complete skeletons being in the minority. As a result, most mounts in museums are composite skeletons. This can cause significant scientific doubt and problems, since, apart from morphology and taphonomy, skeletal unity is difficult to test. Quarries, such as the Howe Ranch quarries (Ayer, 2000) and the Carnegie Quarry, are famous for their good preservation and their abundance of sauropod postcranial skeletons but even in those it can be difficult to precisely assign parts of skeletons, e.g., limbs and tails, and isolated skeletal elements to specific individuals based on the arrangement of the bones in the quarry as revealed and recorded during excavation. Information on skeletal unity is not only crucial for anatomical descriptions and desirable for museum mounts but also important in taphonomic research, e.g., for determining how many individuals are located within a quarry. Also, skeletal unity testing is important when working on sauropod phylogenetics (such as Tschopp et al., 2015) and sauropod completeness assessment (Manion and Upchurch, 2010). The difficulty of ascertaining skeletal unity in sauropods in the Howe Ranch quarries is due to the relatively high number of individuals that had accumulated over time, combined with the uniform and thus poorly diagnostic morphology of sauropod limb bones (Liston, 2004; Griebeler et al., 2013).

The aim of this study is thus to test if histological characters can be used to test skeletal unity within a quarry. We propose a synthetic method combining the various aspects of bone tissue (e.g., bone matrix type, vascularization, growth marks, Haversian substitution), in order to test previous hypotheses of skeletal unity that were based on field observations. We use the sauropod material from two adjacent Morrison quarries in the Bighorn Basin on the Howe Ranch near Greybull (Wyoming) as a case study, i.e., the Howe-Stephens Quarry (Figure 1) and the Howe Scott Quarry (Figure 2) (Ayer, 2000; Michelis, 2004).

\section{INSTITUTIONAL ABBREVIATIONS}

CM: Carnegie Museum of Natural History, Pittsburgh, Pennsylvania, USA

MfN: Museum für Naturkunde, Berlin, Germany SMA: Sauriermuseum Aathal, Aathal, Switzerland

\section{MATERIAL AND METHODS}

\section{Material}

In the Howe Ranch Dinosaur quarries, most of the common Morrison Formation sauropod dinosaur genera are represented. In addition to Camarasaurus and possible Brachiosaurus, there is a diversity of diplodocids, including Galeamopus, Apatosaurus, and indet. diplodocines (Ayer, 2000; Tschopp et al., 2015; Table 1). Histological core samples were obtained by PMS in 2001 and KWW in 2014 by coring (see method in Stein and Sander, 2009) numerous sauropod long bones from both quarries (Table 1), and thin-sections were obtained from each core and are kept in the collections of the SMA and the Institute of Geosciences. Primarily humeri and femora of partial to complete skeletons were sampled, but also zeugopodial bones and isolated long bones not assigned to a skeleton. Twelve cores were taken from Howe-Stephens Quarry bones. The cores represent at least five 


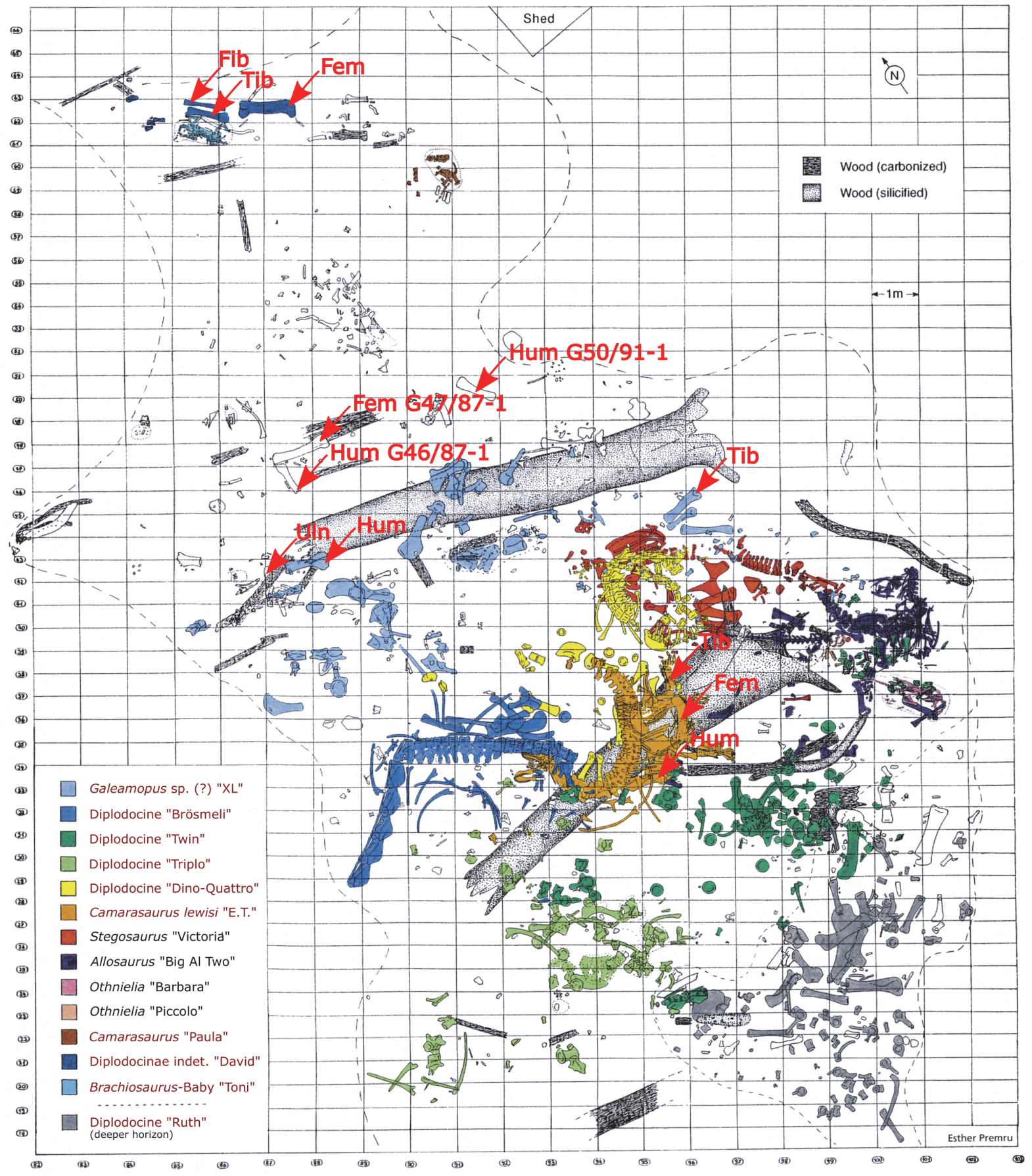

FIGURE 1. Detailed quarry map of the Howe-Stephens Quarry with finds from excavation seasons 1992-2001. The color coding reflects the hypothesis of skeletal unity based on field observations (Ayer, 2000). Sauropods are indicated in red text in the legend. Note that the 2002 season, which was the last season for the Howe-Stephens Quarry, only uncovered another silicified tree trunk, which was found below the partial skeletons of SMA 0002 "E.T." and SMA no \# "Brösmeli". The arrows indicate the sampled bones used in this study. This quarry map was made by E. Premru, and provided by the Sauriermuseum Aathal, Aathal, Switzerland. 
Howe - Scott Quarry (Wyoming, USA)

General Quarry Map 1995 / $2000+2002$ / 2003

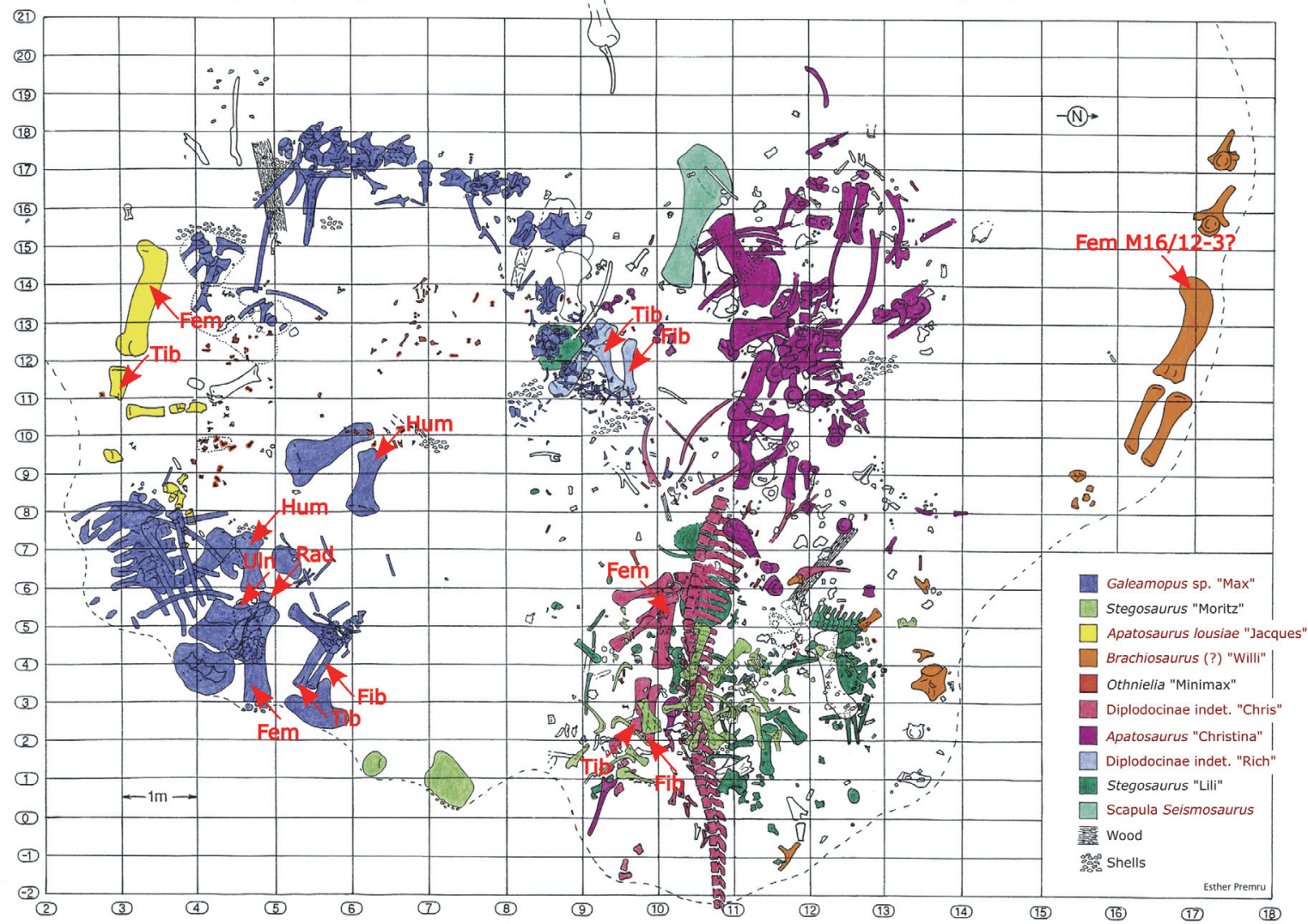

FIGURE 2. Detailed quarry map of the Howe Scott Quarry with finds from excavation seasons 1995-2003. The color coding reflects the hypothesis of skeletal unity based on field observations (Ayer, 2000). Sauropods are indicated in red in the legend. The arrows indicate the sampled bones used in this study. The quarry map was made by E. Premru, and provided by the Sauriermuseum Aathal, Aathal, Switzerland. Note that SMA M16/12-3 is not marked on the map due to a coordinate inaccuracy, which makes it impossible to correctly locate bone SMA M16/12-3 on the quarry map.

individuals according to the quarry map (Figure 1). Similarly, 17 cores were taken from specimens from the Howe Scott Quarry, representing four different individuals according to field observations (Figure 2). An overview of the sampled specimens and measurements is given in Table 1. The control sample, from the Howe-Stephens Quarry, are three cores taken from the completely articulated Camarasaurus lewisi skeleton SMA 0002, nicknamed "E.T.". This specimen constitutes a fully articulated skeleton with a preserved skull (Wiersma and Sander, 2016) and most of the postcrania from the Howe-Stephens Quarry (Figure 1) and was clearly identified as belonging to the species Camarasaurus lewisi (E. Tschopp, pers. commun., 2016). Since this individual is completely articulated, the life history record in the samples should be the same and can therefore be used as a control sample to test the hypothesis of skeletal unity.
The left femur SMA M16/12-3 was sampled, because it was initially assigned to SMA 0011 "Max". However, this assignment was made during excavations before the left femur of SMA 0011 "Max" was found, which is more likely to belong to "Max" than SMA M16/12-3 based on field observations (Figure 2). The left femur SMA M16/12-3 will thus be treated separately and offers a good test of skeletal unity of the material currently assigned to "Max".

\section{Geological Settings}

Howe Ranch Dinosaur Quarries. The sediments of the Howe Ranch Dinosaur quarries are Late Jurassic (Late Tithonian, $145 \mathrm{ma}$ ) in age and pertain to the Morrison Formation. They consist of the classical Howe Quarry, the Howe-Stephens Quarry (G-Pit), and the Howe Scott Quarry (Ayer, 2000; Michelis, 2004). The Howe Ranch is a small private holding located between the Bighorn Basin in the 
TABLE 1. List of the sampled sauropod specimens at the Howe-Stephens and Howe Scott quarries, with taxon assignment (based on field observations and later revised after Tschopp et al., 2015), measurements, bone tissue types, HOS and BOS, RS, number of cycles, presence of an EFS, and the bone surface conditions (OS = original surface, NOS = not original surface). Note that the bone tissue type usually consists of two letters; the first one representing the main bone tissue type that is present in the cortex, and the second one only within the innermost or outermost cortex (Table 3 ). Bone length is here defined as the largest proximal-distal distance within each bone. Both bone width and bone thickness have been taken at the sampling location at the mid-diaphysis. Due to poor preservation, the tibia of SMA 0007 "XL" could not be identified as a left or right tibia. Note that bone width and bone thickness for SMA 0015 "David" tibia and SMA G50/91-1 could not be measured since the bones remained in a plaster jacket and were only partially uncovered for sampling. Femur (I) SMA 0011 "Max", drilled posterior, was sampled by PMS in 2001, when the bone was in preparation; femur (I) SMA 0011 "Max", drilled anteriorly was sampled by KW in 2014, when the bone was no longer in the plaster jacket. The inaccuracies caused by partial coverage by plaster jackets is illustrated by the $\sim$ symbol. Bone width and bone thickness were not measured for the SMA 0087 "Chris" femur ( $r$ ), as well as the bone thickness for SMA M16/12-3, since the bones were still covered in a plaster jacket during sampling.

\begin{tabular}{|c|c|c|c|c|c|c|c|c|c|c|c|c|}
\hline $\begin{array}{c}\text { Specimen } \\
\text { designation }\end{array}$ & Taxon & $\begin{array}{c}\text { State of } \\
\text { preservation }\end{array}$ & $\begin{array}{l}\text { Sampled } \\
\text { bone }\end{array}$ & $\begin{array}{c}\text { Bone } \\
\text { length } \\
\text { (mm) }\end{array}$ & $\begin{array}{l}\begin{array}{l}\text { Bone } \\
\text { width } \\
(\mathrm{mm})\end{array}\end{array}$ & $\begin{array}{c}\text { Bone } \\
\text { thickness } \\
(\mathrm{mm})\end{array}$ & $\begin{array}{c}\text { Bone } \\
\text { tissue } \\
\text { type }\end{array}$ & HOS & BOS & RS & Cycles & $\begin{array}{c}\text { EFS and } \\
\text { bone } \\
\text { surface }\end{array}$ \\
\hline \multicolumn{13}{|c|}{ Howe-Stephens Quarry } \\
\hline \multirow[t]{3}{*}{$\begin{array}{l}\text { SMA } 0002 \\
\text { "E.T." }\end{array}$} & $\begin{array}{l}\text { Camarasaurus } \\
\text { lewisi }\end{array}$ & $\begin{array}{l}\text { Articulated } \\
\text { skeleton }\end{array}$ & $\begin{array}{l}\text { Humerus } \\
\text { (r) }\end{array}$ & 705 & 120 & 82 & G & 13 & Adult III & RS 7 & 0 & Yes, NOS \\
\hline & & & Femur (I) & 935 & 175 & 85 & $\mathrm{~F} / \mathrm{E}$ & 11 & Adult II & RS 2 & 3 & Yes, OS \\
\hline & & & Tibia (I) & 615 & 110 & 60 & F/EFS & 12 & $\begin{array}{l}\text { Adult II to } \\
\text { Adult III }\end{array}$ & RS 3 & 9 & Yes, OS \\
\hline \multirow[t]{3}{*}{ SMA 0007 “XL” } & Galeamopus sp. & $\begin{array}{l}\text { Disarticulated } \\
\text { skeleton }\end{array}$ & $\begin{array}{l}\text { Humerus } \\
(r)\end{array}$ & 925 & 160 & 95 & $E / F$ & 10 & $\begin{array}{l}\text { Adult I to } \\
\text { Adult II }\end{array}$ & RS 3 & 8 & No, OS \\
\hline & & & Ulna (I) & 745 & 100 & 80 & F/EFS & 12 & $\begin{array}{l}\text { Adult II to } \\
\text { Adult III }\end{array}$ & RS 5 & 4 & Yes, NOS \\
\hline & & & Tibia (?) & 980 & 120 & 95 & $\mathrm{~F} / \mathrm{E}$ & 11 & Adult II & RS 4 & 3 & Yes, NOS \\
\hline \multirow[t]{3}{*}{$\begin{array}{l}\text { SMA } 0015 \\
\text { "David" }\end{array}$} & $\begin{array}{l}\text { Diplodocinae } \\
\text { indet. }\end{array}$ & $\begin{array}{l}\text { Articulated } \\
\text { specimen }\end{array}$ & Femur (I) & 1340 & 210 & 95 & $E / F$ & 10 & $\begin{array}{l}\text { Adult I to } \\
\text { Adult II }\end{array}$ & RS 2 & 4 & No, NOS \\
\hline & & & Tibia (I) & 1010 & - & - & $\mathrm{F} / \mathrm{E}$ & 11 & Adult II & RS 4 & 1 & $\begin{array}{c}\text { Just } \\
\text { started, } \\
\text { NOS }\end{array}$ \\
\hline & & & Fibula (I) & 1040 & 80 & 65 & $\mathrm{~F} / \mathrm{E}$ & 11 & Adult II & RS 4 & 7 & Yes, NOS \\
\hline SMA G46/87-1 & $\begin{array}{l}\text { Diplodocinae } \\
\text { indet. }\end{array}$ & Isolated bone & $\begin{array}{l}\text { Humerus } \\
\text { (I) }\end{array}$ & 715 & 140 & 75 & $\mathrm{D} / \mathrm{E}$ & 8 & $\begin{array}{l}\text { Sexual } \\
\text { Maturity }\end{array}$ & RS 1 & 8 & No, NOS \\
\hline SMA G50/91-1 & $\begin{array}{l}\text { Diplodocinae } \\
\text { indet. }\end{array}$ & Isolated bone & $\begin{array}{l}\text { Humerus } \\
(r)\end{array}$ & 735 & - & - & $D / E$ & 8 & Adult I & RS 2 & 9 & No, NOS \\
\hline SMA G47/87-1 & $\begin{array}{l}\text { Diplodocinae } \\
\text { indet. }\end{array}$ & Isolated bone & Femur (I) & 1200 & 175 & 75 & $E / D$ & 9 & $\begin{array}{l}\text { Sexual } \\
\text { Maturity }\end{array}$ & RS 1 & 0 & No, NOS \\
\hline \multicolumn{13}{|c|}{ Howe Scott Quarry } \\
\hline \multirow[t]{3}{*}{$\begin{array}{l}\text { SMA } 0014 \\
\text { "Jacques" }\end{array}$} & $\begin{array}{l}\text { Apatosaurus } \\
\text { louisae }\end{array}$ & $\begin{array}{l}\text { Articulated } \\
\text { specimen }\end{array}$ & $\begin{array}{l}\text { Femur (r) } \\
\text { ant. } \\
\text { section }\end{array}$ & 1640 & 295 & 110 & $E / D$ & 9 & Adult I & RS 3 & 18 & No, NOS \\
\hline & & & $\begin{array}{l}\text { Femur (r) } \\
\text { post. } \\
\text { section }\end{array}$ & 1640 & 295 & 110 & $E / D$ & 9 & Adult I & RS 3 & 18 & No, NOS \\
\hline & & & Tibia (r) & 640 & 175 & 115 & $E / F$ & 10 & $\begin{array}{l}\text { Adult I to } \\
\text { Adult II }\end{array}$ & RS 4 & 9 & No, OS \\
\hline \multirow[t]{5}{*}{$\begin{array}{l}\text { SMA } 0011 \\
\text { "Max" }\end{array}$} & Galeamopus sp. & $\begin{array}{l}\text { Associated } \\
\text { specimen }\end{array}$ & $\begin{array}{l}\text { Humerus } \\
(r)\end{array}$ & 900 & 190 & 80 & $\mathrm{D} / \mathrm{E}$ & 8 & $\begin{array}{l}\text { Sexual } \\
\text { Maturity }\end{array}$ & RS 1 & 10 & No, OS \\
\hline & & & $\begin{array}{l}\text { Humerus } \\
\text { (I) }\end{array}$ & 850 & 180 & 90 & $\mathrm{D} / \mathrm{E}$ & 8 & $\begin{array}{l}\text { Sexual } \\
\text { Maturity }\end{array}$ & RS 1 & 8 & No, NOS \\
\hline & & & Ulna (I) & 635 & 95 & 65 & $E / F$ & 10 & $\begin{array}{l}\text { Adult I to } \\
\text { Adult II }\end{array}$ & RS 3 & 10 & No, OS \\
\hline & & & Radius (I) & 620 & 100 & 65 & $E / F$ & 10 & $\begin{array}{l}\text { Adult I to } \\
\text { Adult II }\end{array}$ & RS 3 & 11 & No, OS \\
\hline & & & $\begin{array}{l}\text { Femur (I) } \\
\text { ant. } \\
\text { section }\end{array}$ & 1490 & 240 & 145 & $\mathrm{D} / \mathrm{E}$ & 8 & $\begin{array}{l}\text { Sexual } \\
\text { Maturity }\end{array}$ & RS 1 & 13 & No, OS \\
\hline
\end{tabular}


TABLE 1 (continued).

\begin{tabular}{|c|c|c|c|c|c|c|c|c|c|c|c|c|}
\hline $\begin{array}{l}\text { Specimen } \\
\text { designation }\end{array}$ & Taxon & $\begin{array}{c}\text { State of } \\
\text { preservation }\end{array}$ & $\begin{array}{l}\text { Sampled } \\
\text { bone }\end{array}$ & $\begin{array}{c}\text { Bone } \\
\text { length } \\
\text { (mm) }\end{array}$ & $\begin{array}{l}\text { Bone } \\
\text { width } \\
(\mathrm{mm})\end{array}$ & $\begin{array}{c}\text { Bone } \\
\text { thickness } \\
(\mathrm{mm})\end{array}$ & $\begin{array}{c}\text { Bone } \\
\text { tissue } \\
\text { type }\end{array}$ & HOS & BOS & RS & Cycles & $\begin{array}{c}\text { EFS and } \\
\text { bone } \\
\text { surface }\end{array}$ \\
\hline \multicolumn{13}{|c|}{ Howe Scott Quarry } \\
\hline & & & $\begin{array}{l}\text { Femur (I) } \\
\text { post. } \\
\text { section }\end{array}$ & 1490 & 240 & 145 & $\mathrm{D} / \mathrm{E}$ & 8 & $\begin{array}{l}\text { Sexual } \\
\text { Maturity }\end{array}$ & RS 1 & 11 & No, NOS \\
\hline & & & Tibia (I) & 870 & 80 & 140 & $E / D$ & 9 & Adult I & RS 3 & 9 & No, OS \\
\hline & & & Fibula (I) & 870 & 90 & 60 & $E / D$ & 9 & Adult I & RS 3 & 8 & No, OS \\
\hline SMA M16/12-3 & $\begin{array}{l}\text { Diplodocinae } \\
\text { indet.? }\end{array}$ & Isolated bone & Femur (I) & 1250 & 225 & - & $\mathrm{F} / \mathrm{E}$ & 11 & Adult II & RS 3 & 2 & Yes, NOS \\
\hline \multirow[t]{2}{*}{$\begin{array}{l}\text { SMA } 0084 \\
\text { "Rich" }\end{array}$} & $\begin{array}{l}\text { Diplodocinae n. } \\
\text { gen. et } n . \text { sp. }\end{array}$ & $\begin{array}{l}\text { Articulated } \\
\text { specimen }\end{array}$ & Tibia (I) & 725 & 135 & 80 & G & 13 & Adult III & RS 7 & 1 & Yes, NOS \\
\hline & & & Fibula (I) & 800 & 80 & 50 & G & 13 & Adult III & RS 7 & 0 & Yes, NOS \\
\hline \multirow[t]{3}{*}{$\begin{array}{l}\text { SMA } 0087 \\
\text { "Chris" }\end{array}$} & $\begin{array}{l}\text { Diplodocinae n. } \\
\text { gen. et } n . \text { sp. }\end{array}$ & $\begin{array}{l}\text { Articulated } \\
\text { specimen }\end{array}$ & Femur $(r)$ & 1440 & - & - & $\mathrm{E} / \mathrm{F}$ & 10 & Adult I & RS 2 & 6 & Yes, NOS \\
\hline & & & Tibia (r) & 750 & 140 & $\sim 110$ & G & 13 & Adult III & RS 7 & 2 & Yes, NOS \\
\hline & & & Fibula (r) & 800 & 100 & $\sim 70$ & G & 13 & Adult III & RS 7 & 0 & Yes, NOS \\
\hline
\end{tabular}

west and the Bighorn Mountains in the east of Wyoming, USA. The Howe Ranch Dinosaur quarries are the main fossil lagerstätte in this region where dinosaur bones and fossil plants are associated in the same bed (Turner and Peterson, 1999; Ayer, 2000; Ikejiri, 2002; Michelis, 2004; Ikejiri et al., 2005; Gee, 2010). A review of the history of excavations is presented to understand the hypotheses of skeletal unity, which were based on field observations, i.e., quarry maps.

History of the Howe Ranch Dinosaur quarries. Between 1932-1934, Barnum Brown of American Museum of Natural History fame and his team excavated approximately 4000 dinosaur bones from the Howe Quarry (Sinclair Dinosaur Expedition) until the fossils began to thin out in 1934 (Brown, 1935; Breithaupt, 1997; Michelis, 2004). In 1990 , author HJS and his team from the Sauriermuseum Aathal, Switzerland, leased the fossil rights on the Howe Ranch with the intention of reopening Brown's classical Howe Quarry. While abundant fossils were found, long bones were rare and the deposit was exhausted by 1991. In 1992, after prospecting the area around the Howe Quarry, the Swiss team opened up a new quarry about $450 \mathrm{~m}$ to the southwest. This site was called the Howe-Stephens Quarry "G-Pit" and was found to be particularly fossil-rich. The beds of the HoweStephens Quarry and Howe Scott Quarry are vertically dispersed and the Howe-Stephens Quarry beds are therefore located several meters above those of the Howe Quarry and are somewhat younger in geologic age (Ayer, 2000). The HoweStephens Quarry is roughly $20 \mathrm{~m}$ in diameter and includes articulated and/or associated partial to complete skeletons, and some isolated bones from possibly 14 individuals of different taxa (Figure 1) excavated between 1992 and 2001 (Ayer, 2000). The hypothesized individuals based on field observations and provided with nicknames for the ease of communication are color-coded on the quarry map (Figure 1). The individuals represent many well-known Morrison Formation dinosaur taxa, such as diplodocine sauropods, Camarasaurus, Stegosaurus, Allosaurus, and Othnielia (Ayer, 2000).

In 1995, a new quarry was opened, which is located some tens of meters northeast of the Howe-Stephens Quarry "G-Pit". This quarry was initially named the Howe-Stephens Quarry "M-Pit" (Figure 2), and later became the Howe Scott Quarry, in honor of one of the current owners of the Howe Ranch. The Howe Scott Quarry is $16 \mathrm{~m}$ by $11 \mathrm{~m}$, and also contains articulated and associated skeletons. During the excavation seasons of 1995 to 2003 , a total of 10 putative individuals of various species such as Apatosaurus, Galeamopus, Stegosaurus, and Othnielia (Ayer, 2000; Tschopp et al., 2015), were recovered and are color-coded on the Howe Scott Quarry map (Figure 2).

Sedimentology, stratigraphy, and taphonomy of the Howe-Stephens and Howe Scott quarries. The Morrison Formation at the Howe Ranch is about $60 \mathrm{~m}$ thick and consists mainly of yellow marls and sandstones with some rare layers of carbonate, some intercalated grey or violet bentonites, and reddish and greenish marls (Ayer, 2000; Michelis, 2004). A subdivision of the Morrison Formation into the members recognized further south was not possible (Michelis, 2004). The sediments 
at the Howe Ranch represent the fluvial depositional environment common in the Morrison Formation elsewhere (Ayer, 2000; Michelis, 2004). Sedimentological evidence indicates that the Howe-Stephens and Howe Scott quarries are in a braided river setting with sandbars in the Howe Ranch area (Ayer, 2000; Michelis, 2004). Based on current indicators in the sandstone, the flow direction of the river was from southwest to northeast (Ayer, 2000).

A general taphonomical interpretation of the Howe-Stephens and Howe Scott quarries is that the large amount of skeletons found in these quarries is the result of several flood events (Ayer, 2000). The carcasses were transported by the river before being deposited on the river bars. Some skeletons were trapped behind a large tree trunk (Figure 1). The different kinds of preservations of the skeletons in the Howe-Stephens and Howe Scott quarries are possibly due to the different deposition rates. However, a detailed taphonomic study for the Howe-Stephens and Howe Scott quarries has yet to be conducted.

\section{Technical Processing of the Samples}

Linear measurements. Each sampled bone was measured and photographed in order to compare histological evidence with skeletal element size. These measurements include the maximal length of the bone between the epiphyses, as well as the bone width (medial-lateral) and thickness (anteriorposterior) at the sampling location at mid-diaphysis (Table 1).

Sampling and thin-sectioning. Bone samples were taken using the standard core-drilling method previously established by Sander (2000) during his work on the Tendaguru sauropods and described in detail by Stein and Sander (2009). Cores were systematically taken at a standardized (homologous) location corresponding to the mid-diaphysis of the limb bones, where the thickest and concurrently oldest cortex with the most complete growth record is preserved (see de Ricqlès, 1983; Chinsamy, 1993; Klein and Sander, 2007, 2008; Stein and Sander, 2009, Figure 1).

The standard sampling location for humeri is the posterior side of the mid-shaft, and for the femora the anterior side of the mid-shaft (Sander, 2000; Klein et al., 2012). To illustrate the intra-skeletal element histovariability and thus the importance of standardized sampling locations, two femora (SMA 0011 "Max" and SMA 0014 "Jacques") were sampled both at the anterior and posterior midshaft region. Radii and ulnae have not yet been used systematically for such histological studies, so the anterior mid-shaft region of the only sampled radius and the lateral mid-shaft region of the ulnae were chosen for sampling due to the thickest cortex observed in these regions. Tibial and fibular cores were taken from the anterior midshaft region of the bones, where the sampling location of the tibiae was located slightly towards the distal end, and that of the fibulae slightly proximal (Klein and Sander, 2007). Thin sections and polished core halves were processed for each sample at the bone histological lab of the Institute of Geosciences, University of Bonn, Germany, using standard petrographic techniques (Lamm, 2013).

For observation and illustration of the thinsections, a Leica DMPL polarization microscope (16x to 400x magnification) and a Leica DFC420 digital camera were used. Polished sections were studied using a stereo microscope. Digital images were processed with ImageAccess easyLab 7 software (2007 edition), and scans of the section were made with an EPSON V750 high-resolution scanner.

\section{Histological Methods}

To test hypotheses of skeletal unity, several previously established methods were used and combined in this study. While not completely independent of each other, these methods rely on different aspects of bone microstructure, such as the growth record, the change in bone tissue organization during ontogeny, and the extent of remodeling. The combination of these histological features, together with morphology and taphonomy, can then clarify hypothesized skeletal unity. Histological observations follow Francillon-Vieillot et al. (1990) and Klein and Sander (2008) and are summarized in Table 1.

Histological ontogenetic stages (HOS). The study of life history in sauropod long bones, and with that age determination, is challenging due to the fact that growth marks are relatively rare and inconsistently expressed (Sander, 2000; Sander and Tückmantel, 2003; Klein and Sander, 2008; Sander et al., 2011b). This problem can be solved by the use of histological ontogenetic stages (HOS) (Klein and Sander, 2008).

Klein and Sander (2008) provided a comparative assessment of histological changes in the growth series of several sauropod taxa, so an estimated ontogenetic status can be given for sauropod long bone samples where growth marks are lacking. All sauropod long bone cortices mainly consist of fibrolamellar bone, which grew fairly uni- 
formly fast. However, in the sauropod cortices, differences can be observed concerning the local organization of the vascular system, the degree of vascularization, the presence and degree of development of primary osteons, and the number of secondary osteons (thus the intensity of Haversian substitution; Klein and Sander 2008). Using these bone features, Klein and Sander (2008) identified seven bone tissue types (type $A$ to $G$ ), reflecting progressive changes in bone tissue organization through ontogeny (Table 2; see also Klein and Sander, 2008).

The transition between the different bone tissue types is gradual, and thus most cortices contain two to three tissue types in sequence (Klein and Sander, 2008). Klein and Sander (2008) used this pattern to establish $13 \mathrm{HOS}$ corresponding to various combinations of bone tissue types (Table 3). The identification of HOS allows estimating the ontogenetic stage of a given skeletal element. Note that the HOS were originally defined for humeri and femora by Klein and Sander (2008), not for bones of the zeugopodium. However, we apply them to zeugopodial bones as well under the general assumption that the thinner cortex of the zeugopodial bones will show a higher HOS then the stylopodial bones (see also below).

The HOS were then later combined with biologic ontogenetic stages (BOS) by Sander et al. (2011b), allowing an estimate of the ontogenetic status of a sauropod individual. The terms used to define BOS originate from the study of life history in extant amniotes (Klein and Sander, 2008), however, BOS stages Adult I to Adult III were introduced by Sander et al. (2011b).

The method of HOS/BOS identifications developed by Klein and Sander (2008) and Sander et al. (2011b) will be applied to all sampled long bones and can then be used to test skeletal unity, since bones from one individual, e.g., left and right femora, should show the same HOS and thus BOS. However, a problem that occurs when comparing bones of a single individual, is that smaller bones (here represented by the zeugopodial elements) generally possess thinner cortices, and are therefore remodeled faster than the larger, thicker bones despite being the product of the same life history (Mitchell and Sander, 2014; Padian et al., 2016). This leads to a higher HOS for the zeugopodial elements compared to that of stylopodial element, even though they may belong to the same individual. Yet, when testing skeletal unity, this method can still be used by means of exclusion: If a smaller (zeugopodial) bone shows a younger
HOS than a larger (stylopodial) bone, skeletal unity can be rejected.

Remodeling. In limb bones of old individual, the cortex of which has been completely remodeled, the only features that can be observed are secondary osteons (Mitchell and Sander, 2014; Mitchell et al., 2017). Mitchell et al. (2017) therefore developed a method to subdivide late ontogeny by means of features of remodeling, resulting in remodeling stages (RS) for humeri and femora (Figure 3). RS from 1 to 15 (Table 4) were assigned to each sampled limb bones in this study following Mitchell et al. (2017). However, here, the problem of smaller bones remodeling faster than the larger bones also applies. Yet, by means of exclusion, this method can still be used to test skeletal unity. Thus, if an ulna possesses a lower number of generations of secondary osteons than the humerus, it is very unlikely that these bones belonged to the same individual.

Growth marks and growth cycles. Growth marks indicate a cyclical variation or pause in the rate of growth of a given long bone (Sander et al., 2011b; Padian and Lamm, 2013; Woodward et al., 2013). They are relatively rare in sauropod long bones (Sander et al., 2004; Klein and Sander, 2008; Sander et al., 2011b; Waskow and Sander, 2014) due to the fast growth and sometimes extensive remodeling of the primary cortex of these animals. When present, four types of growth marks can occur within compact bone of sauropod dinosaurs: i) well-vascularized zones (faster growth) alternating with slower-growing annuli (Francillon-Vieillot et al., 1990; de Ricqlès et al., 1991; Castanet et al., 1993; Castanet, 1994; Sander et al., 2011b); ii) modulations corresponding to local variations in the orientation and/or density of vascularization and thus representing a subtle change in depositional rate (de Ricqlès, 1983; Rimblot-Baly et al., 1995; Curry, 1999; Sander et al., 2011b); iii) polish lines corresponding to subtle cessations of growth that occur within fibrolamellar bone (Sander, 2000; Sander et al., 2011b). They can only be observed in polished sections (Sander, 2000) where they mark an abrupt softening of the fossil bone, which can be detected as a decrease of reflectivity. (Sander, 2000; Sander and Tückmantel, 2003; Klein and Sander, 2007, 2008; Sander et al., 2011b); iv) clear lines of arrested growth (LAGs), representing a complete cessation of growth for a certain amount of time (Francillon-Vieillot et al., 1990). Note that the annual formation of annuli and LAGs has been well documented, yet the annual 
TABLE 2. Description of the seven bone tissue types A-G occuring in the cortices of sauropod long bones (after Klein and Sander, 2008).

\begin{tabular}{|c|c|c|c|c|c|}
\hline $\begin{array}{c}\text { Bone } \\
\text { tissue } \\
\text { type }\end{array}$ & $\begin{array}{c}\text { Bone } \\
\text { organization }\end{array}$ & $\begin{array}{l}\text { Vascular canal } \\
\text { organization }\end{array}$ & Primary osteons & Secondary osteons & $\begin{array}{l}\text { Growth marks } \\
\text { and EFS }\end{array}$ \\
\hline A & Non-laminar & - & - & - & - \\
\hline B & $\begin{array}{l}\text { Woven } \\
\text { fibrolamellar bone }\end{array}$ & $\begin{array}{l}\text { Mostly longitudinal, high } \\
\text { density }\end{array}$ & - & - & - \\
\hline $\mathrm{C}$ & $\begin{array}{l}\text { Laminar } \\
\text { fibrolamellar }\end{array}$ & $\begin{array}{l}\text { Mostly circumferential, less } \\
\text { dense than in tissue B }\end{array}$ & $\begin{array}{l}\text { Starting to form, } \\
\text { lamellar bone } \\
\text { lining starts to form }\end{array}$ & - & - \\
\hline $\mathrm{D}$ & $\begin{array}{l}\text { Laminar } \\
\text { fibrolamellar }\end{array}$ & $\begin{array}{l}\text { Mostly laminar, less dense } \\
\text { than in tissue C }\end{array}$ & $\begin{array}{l}\text { Present, increase } \\
\text { in lamellar bone } \\
\text { lining }\end{array}$ & $\begin{array}{l}\text { Large, open } \\
\text { ("young") }\end{array}$ & - \\
\hline$E$ & $\begin{array}{l}\text { Laminar } \\
\text { fibrolamellar }\end{array}$ & $\begin{array}{l}\text { Mostly laminar, less dense } \\
\text { than in tissue D }\end{array}$ & $\begin{array}{l}\text { Distinctive, } \\
\text { increase in } \\
\text { lamellar bone } \\
\text { lining }\end{array}$ & $\begin{array}{l}\text { Denser than in tissue } \\
\mathrm{E} \text {, remodeling up to } \\
\text { middle of primary } \\
\text { cortex }\end{array}$ & May rarely occur \\
\hline $\mathrm{F}$ & $\begin{array}{l}\text { Laminar } \\
\text { fibrolamellar }\end{array}$ & $\begin{array}{l}\text { Mostly laminar, clear } \\
\text { decrease in density }\end{array}$ & $\begin{array}{l}\text { Distinctive, nearly } \\
\text { completely filled by } \\
\text { lamellar bone }\end{array}$ & $\begin{array}{l}\text { Dense, distinctive, } \\
\text { remodeling up to } \\
\text { two-thirds of primary } \\
\text { bone }\end{array}$ & $\begin{array}{l}\text { Both may be } \\
\text { present }\end{array}$ \\
\hline G & Haversian & If present, mostly laminar & $\begin{array}{l}\text { If present, } \\
\text { distinctive }\end{array}$ & $\begin{array}{l}\text { Dense, distinctive, } \\
\text { nearly completely } \\
\text { remodeled primary } \\
\text { cortex }\end{array}$ & Both present \\
\hline
\end{tabular}

TABLE 3. The $13 \mathrm{HOS}$ and their correlated BOS, with the seven bone tissue types (after Klein and Sander 2008; Sander et al. 2011b).

\begin{tabular}{lll}
\hline \multicolumn{1}{c}{ Bone tissue type } & HOS & \multicolumn{1}{c}{ BOS } \\
\hline Type A & HOS 1 & Embryo \\
Primarily type A, with type B in outer cortex & HOS 2 & Embryo to Hatchling \\
Primarily type B, with type A in inner cortex & HOS 3 & Hatchling \\
Primarily type B, with type C in outer cortex & HOS 4 & Hatchling to Juvenile \\
Primarily type C, with type B in inner cortex & HOS 5 & Juvenile \\
Primarily type C, with type D in outer cortex & HOS 6 & Juvenile to Subadult \\
Primarily type D, with type C in inner cortex & HOS 7 & Subadult \\
Primarily type D, with type E in outer cortex & HOS 8 & Sexual Maturity \\
Primarily type E, with type D in inner cortex & HOS 9 & Adult I \\
Primarily type E, with type F in outer cortex & HOS 10 & Adult I to Adult II \\
Primarily type F, with type E in inner cortex & HOS 11 & Adult II \\
Primarily type F, with EFS in outer cortex & HOS 12 & Adult II to Adult III \\
Type G & HOS 13 & Adult III \\
\hline
\end{tabular}

formation of modulations and polish lines has not been entirely validated.

In the present study, all types of growth marks were treated equally. Only the number of growth marks (not the type) observed was recorded in Table 1 . In the case of multiple, closely spaced LAGs (as shown in Figure 4), we considered these as a single growth mark. Moreover, the observed growth cycles were numbered in increasing order from the outermost to the inner cortex. Although this numeration is opposite to the usual one tracking life history, it was chosen to best compare the cyclical patterns of different samples, since the inner cycles may be resorbed due to remodeling and the expansion of the medullary cavity (Mitchell and Sander, 2014).

The cyclicity was thus used, in combination with the previously described methods in this 


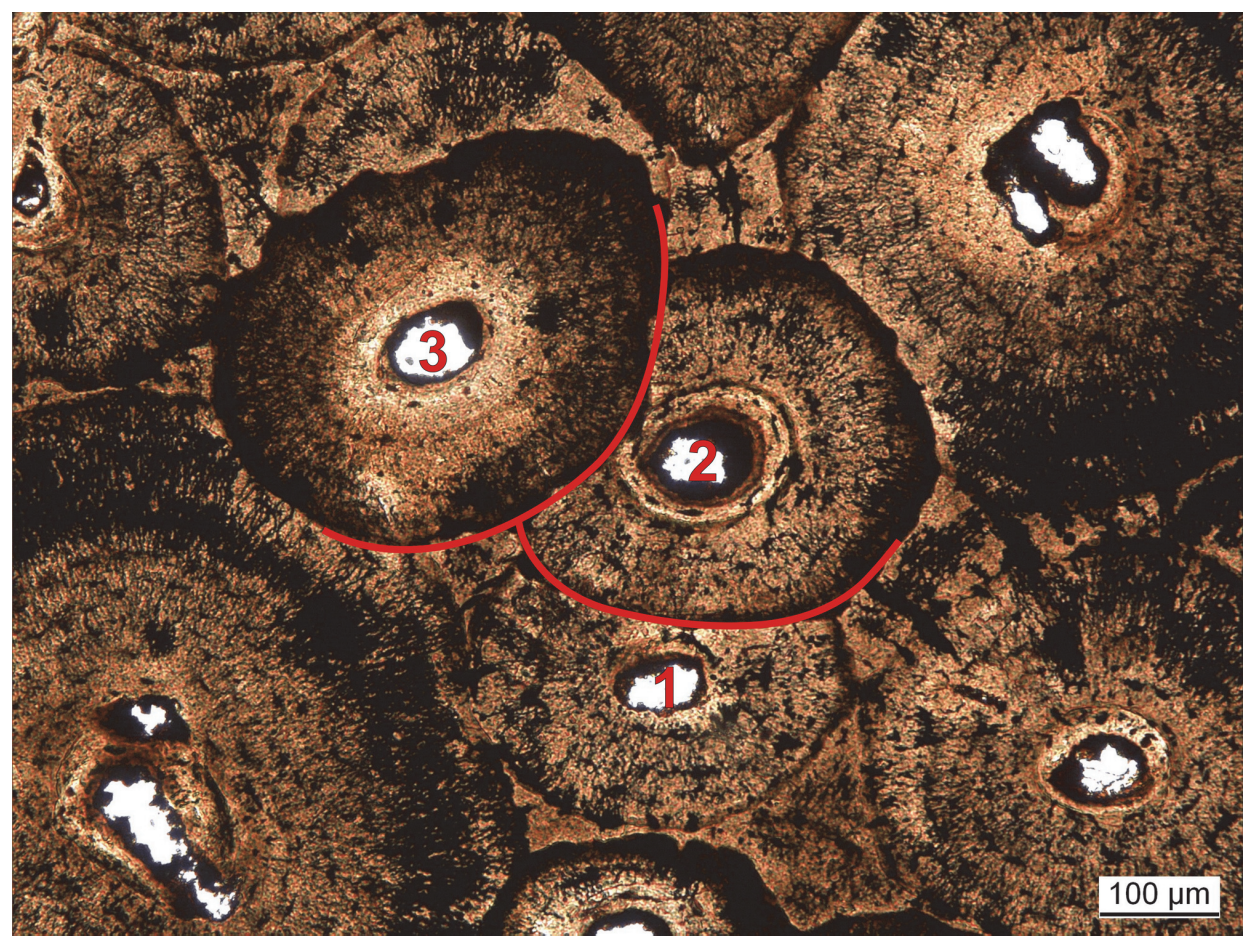

FIGURE 3. The innermost cortex of fibula SMA 0084 "Rich" with the three visible generations of secondary osteons. The numbers indicate the three overlapping secondary osteons. Image taken under plane-polarized light.

study, to test skeletal unity. Since the bones from one individual undergo the same life history, it should be possible to correlate the cyclical patterns recorded in the bones, similar to the principle underlying dendrochronology.

External fundamental system (EFS). When individuals approach final size, the space between growth marks decreases in thickness, which indicates that the amount of bone tissue deposited decreases per unit of time. In some vertebrates, several closely spaced LAGs, alternating with thin layers of lamellar bone can be observed in the outermost cortex. This is known as the external fundamental system (EFS) that indicates a drastic decrease of centrifugal growth and that the animal had reached skeletal maturity (Erickson, 2005, 2014; Sander et al., 2011b; Padian and Lamm, 2013).

It is often difficult to count the number of LAGs in the EFS because of their narrow spacing and variable distinctiveness. Moreover, the bone surface, including the EFS, may have been damaged before, during, or after burial by various processes, resulting in the apparent lack of an EFS. Usually, such damage is recognizable in thin sections, and for this study, we only recorded the presence/ absence of an EFS when the original bone surface clearly was uncompromised.
TABLE 4. Remodeling Stages (RS), based on the maximum number of generations of secondary osteons in the inner, middle, and outer cortex (after Mitchell et al. 2017).

\begin{tabular}{cccc}
\hline \multicolumn{2}{c}{ Generations of secondary osteons } & RS \\
Inner cortex & Middle cortex & Outer cortex & \\
\hline 0 & 0 & 0 & 0 \\
1 & 0 & 0 & 1 \\
1 & 1 & 0 & 2 \\
2 & 1 & 0 & 3 \\
2 & 1 & 1 & 4 \\
2 & 2 & 1 & 5 \\
3 & 2 & 1 & 6 \\
3 & 2 & 2 & 7 \\
3 & 3 & 2 & 8 \\
4 & 3 & 2 & 9 \\
4 & 3 & 3 & 10 \\
4 & 4 & 3 & 11 \\
$4-5$ & 4 & 4 & 12 \\
$4-5$ & 5 & 4 & 13 \\
$4-5$ & 5 & 5 & 14 \\
$4-5$ & 6 & 5 & 15 \\
\hline
\end{tabular}




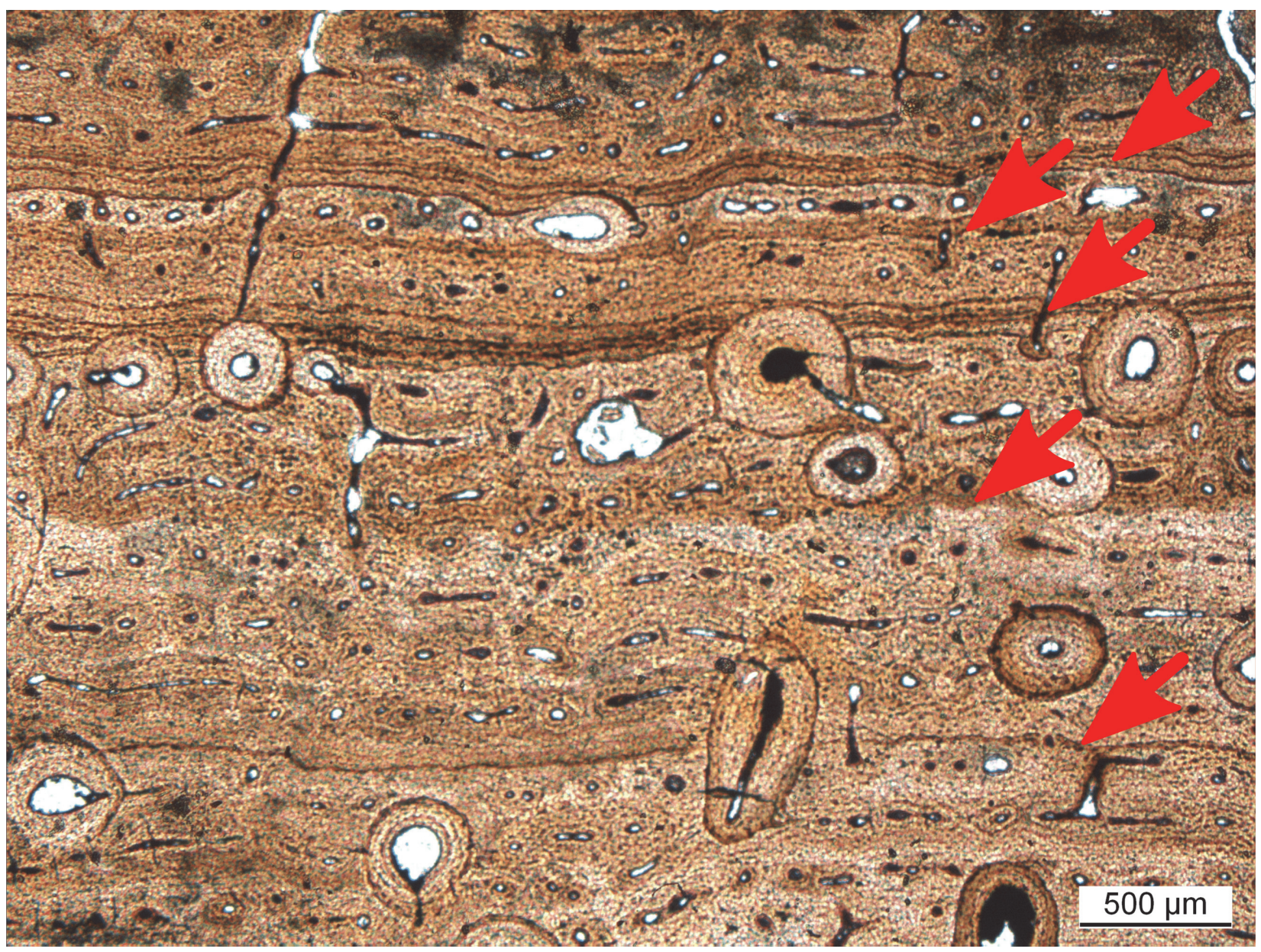

FIGURE 4. Growth marks preserved in the femur of SMA 0087 "Chris". To study the cyclicity, all growth marks are considered. Multiple, closely spaced LAGs (arrows) were counted as one growth mark.

\section{RESULTS}

\section{Histological Observations}

In this section, the histological observations are presented by hypothesized individual and organized by: general histological description, HOS, remodeling stages, and growth marks. Afterwards, the histological evidence is summarized and compared to the evidence from excavation and preparation as compiled in the quarry maps. See Table 1 for a summary of the results for each sampled bone.

SMA 0002 "E.T.", Camarasaurus lewisi. "E.T." represents an articulated individual. Table 1 lists all sampled bones from this specimen.

The femur and tibia bone cores are comprised of the cortex and parts of the medullary cavity (Figure $5 B, 5 C$ ), whereas the core sample from the humerus contains the entire medullary cavity and parts of the cortex on the opposite side of the sampling location (Figure 5A). In general, the histologi- cal features that can be observed in the sampled bones from SMA 0002 "E.T." are congruent. When preserved, the primary bone contains narrow and circumferential primary osteons, but most of the primary bone tissue has been remodeled, and Haversian bone (with longitudinally oriented secondary osteons) is extensive. Growth marks are, however, well expressed in the cortex of the femur and the tibia.

The humeral cortex is completely formed of bone tissue type $\mathrm{G}$ (Figure 5A), which corresponds to HOS 13 and BOS Adult III. The femur primarily consists of bone tissue type $\mathrm{F}$ (Figure 5B). However, remains of tissue type $E$ are still present in the inner cortex. This correlates with HOS 11 and BOS Adult II. Bone tissue type $\mathrm{F}$ dominates in the tibia, and an EFS is deposited in the outermost cortex (Figure 5C). This corresponds to HOS 12 and BOS Adult II to Adult III. SMA 0002 thus was an old individual of BOS Adult II to Adult III. 
A

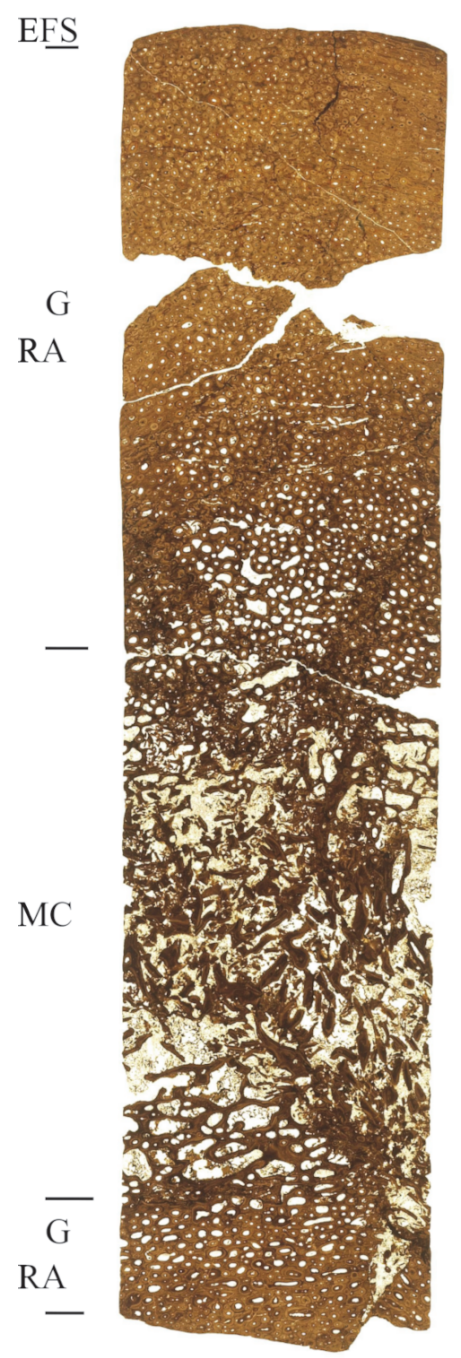

B

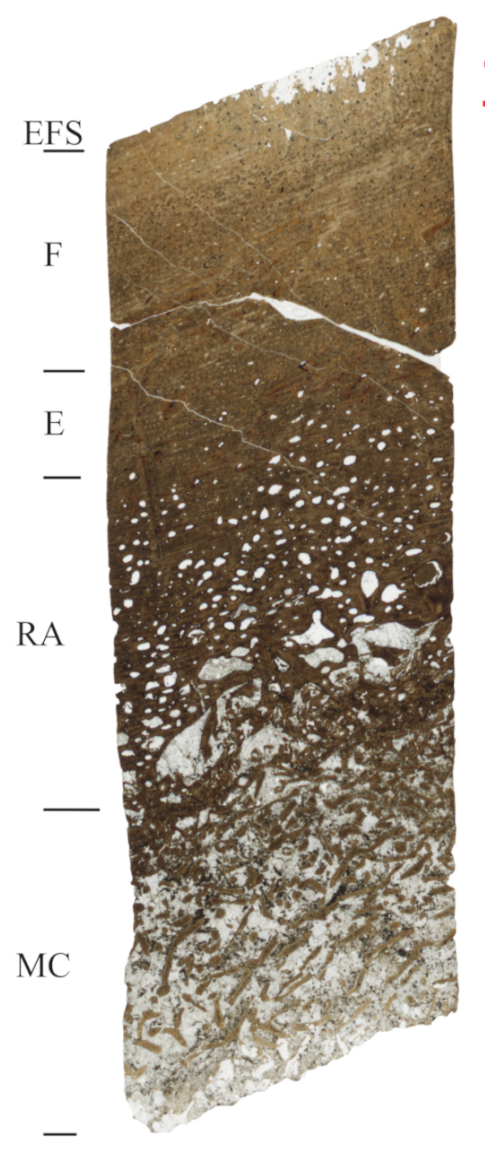

C

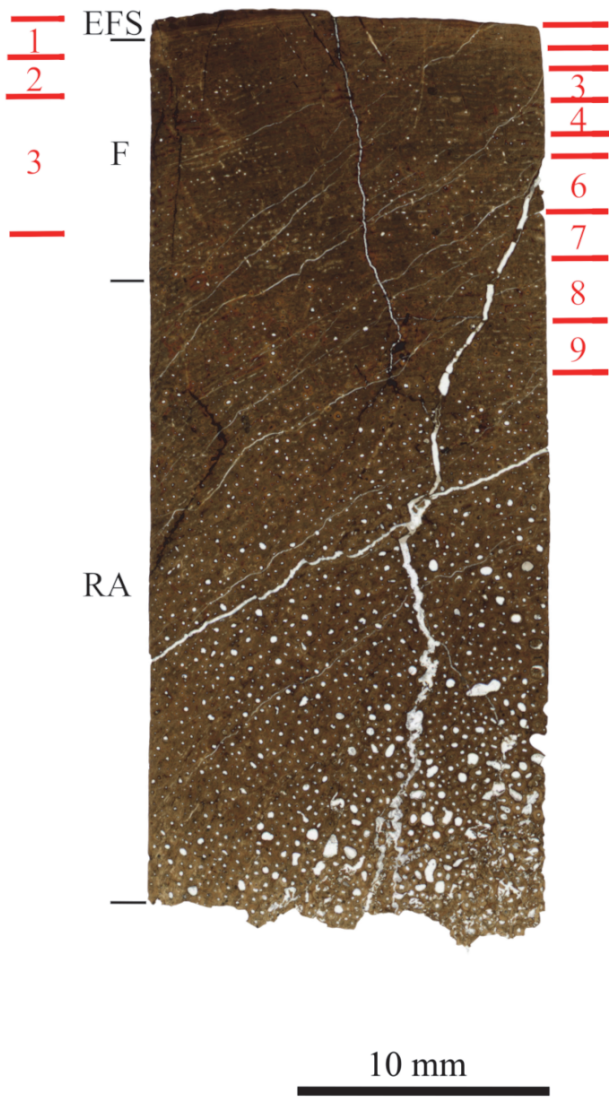

FIGURE 5. Images of all samples taken from SMA 0002 "E.T." A, humerus (r). B, femur (I). C, tibia (I). For all samples, the bone tissue types are indicated to the left, and the number and patterns of the visible growth cycles are indicated to the right. Abbreviations; E: Bone tissue type E, EFS: External fundamental system, F: Bone tissue type F, G: Bone tissue type G, MC: Medullary cavity, RA: Remodeled area.

All three sampled bones show a heavily remodeled cortex. The cortex of the humerus consists of secondary osteons, with mostly two, and in the inner cortex three generations (RS 7) of secondary osteons, which is consistent with bone tissue type $G$ and HOS 13. The least remodeled bone is the femur, which is only $50 \%$ remodeled by one generation of secondary osteons (RS 2). Sixty percent of the primary cortex of the tibia has been remodeled, and the secondary osteons show mostly one, and sometimes two generations (RS $3)$.

Several growth marks are preserved in both the femur and tibia of SMA 0002 (Table 1, Figure
$5 \mathrm{~B}$ and $5 \mathrm{C}$ ). Even though the number of growth marks varies between the cortices of both elements, probably due to a differential extent of remodeling, the number of LAGs (11-13) in both EFSs is roughly the same. The femur shows three cycles, and the tibia shows nine cycles. The humerus only shows the EFS and no cycles due to the heavy remodeling. The number of LAGs present in the humerus EFS cannot be counted, also due to the heavy remodeling.

SMA 0007 "XL", Galeamopus sp. This specimen constitutes a disarticulated and incomplete skeleton from the Howe-Stephens Quarry (Figure 1) of a Galeomopus sp.; however, the taxonomy has to be 
studied in more detail (E. Tschopp, pers. commun., 2016). The tibia could not be identified as left or right due to poor preservation. Table 1 lists all sampled bones from this specimen.

In general, the histology of the humerus and tibia is similar, whereas that of the ulna looks slightly different (Figure 6). The ulna does not possess a primary laminar bone structure, because most of the cortex has been remodeled, and the primary osteons are almost only longitudinally oriented.

The humerus consists primarily of bone tissue type $E$, with tissue type $F$ laid down in the outermost cortex (Figure 6A). This corresponds to HOS 10 and BOS Adult I to Adult II. The ulna is made of bone tissue type $F$, and an EFS is visible (Figure 6B), which correlates with HOS 12 and BOS Adult II to Adult III. Bone tissue type $F$ is also the main tissue found in the tibia (Figure 6C), although bone tissue type $E$ can still be found in the inner cortex. Therefore, the tibia is in stages HOS 11 and BOS Adult II. SMA 0007 thus was an old individual of BOS Adult II.

Haversian substitution is important in all three samples. The humerus represents the least remodeled sample, and $45 \%$ of the primary cortex has been remodeled by secondary osteons of one and sometimes two generations (RS 3). The ulna is the most heavily remodeled bone that was sampled; $75 \%$ of the cortex is remodeled by secondary osteons, which show one to two generations (RS 5). Sixty-five percent of the primary cortex of the tibia is remodeled, and one to two generations of secondary osteons occur (RS 4).

Growth marks can be observed in all three sampled bones (Table 1). All the samples show LAGs in the outer cortex, yet, their number varies slightly. In both the ulna and the tibia, an EFS is present, however, it is more developed in the ulna and just started developing in the tibia. The humerus does not show an EFS. Both the humerus (eight) and the ulna (four) show the highest number of growth cycles, whereas the tibia only shows three. The cyclicity pattern of the humerus and the ulna can be correlated (Figure 6), yet that of the tibia differs slightly.

SMA 0015 "David”, Diplodocinae indet. This specimen corresponds to disarticulated limb bones that nonetheless seem to be still in connection and all from the left hind limb (Figure 1). Table 1 lists all sampled bones from this specimen.

The general histology of the three samples from SMA 0015 "David" (Figure 7) appears very much the same. They all possess primary bone tis- sue with narrow, circumferential primary osteons with some preserved growth marks preserved. Characteristic for these three samples is the orange diagenetic coloration (Figure 8), which cannot be observed in most of the other Howe-Stephens Quarry samples.

The femur consists primarily of bone tissue type $E$, with tissue type $F$ laid down in the outer cortex (Figure 7A). This correlates with HOS 10 and BOS Adult I to Adult II. The cortices of both the tibia and fibula possess mainly bone tissue type $F$, with remains of tissue type $E$ in the inner cortex (Figure 7B and 7C). Therefore, the tibia and fibula correspond to HOS 11 and BOS Adult II. SMA 0015 thus was a mature individual of BOS Adult I.

Remodeling of the femur has progressed up to $30 \%$ of the primary cortex. Only one generation of secondary osteons is present (RS 2). Both the tibia and fibula have been remodeled up to $70 \%$ of the cortex, with the tibia being slightly more remodeled. In both bones, mostly one generation of secondary osteons can be found. However, some rare cases of two generations can also be observed in the inner cortex (RS 4).

Growth marks are present in the cortices of all samples of SMA 0015 "David". Also, the appearance of the first LAGs of an EFS is visible in the tibia and fibula. The femur of "David" shows four cycles, whereas the tibia shows only one cycle and the fibula seven cycles.

Isolated Diplodocinae indet. bones. Three isolated Diplodocinae indet. bones were sampled from the Howe-Stephens Quarry (Table 1, Figure 9). All three bones, although being close to each other according to the quarry map (Figure 1), were not assigned to an individual during excavations.

In general, the histology of the three isolated bones is very similar. They all possess a large amount of primary bone with relatively narrow circumferential primary osteons, resulting in laminar fibrolamellar bone. LAGs are rare in all three samples. Small differences between the samples do occur; humerus SMA G50/91-1 possesses a band of secondary osteons at about two-third of the primary cortex (Figure 10). This band cannot be seen in both of the other samples. Vascular density also varies between the samples, and it is denser in both humeri and less dense in the femur.

Humeri SMA G46/87-1 and SMA G50/91-1 have similar lengths, and their cortices consist primarily of bone tissue type $D$, with tissue type $E$ laid down in the outer cortices (Figure 9A and 9B), which correlates with HOS 8 . The cortex of femur SMA G47/87-1 possesses mostly bone tissue type 
A

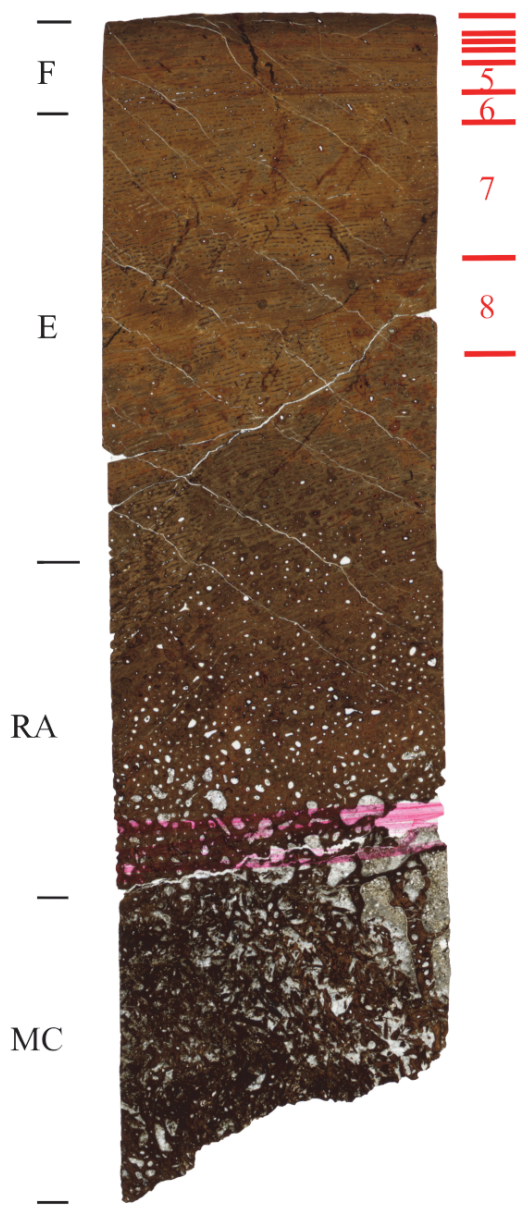

B

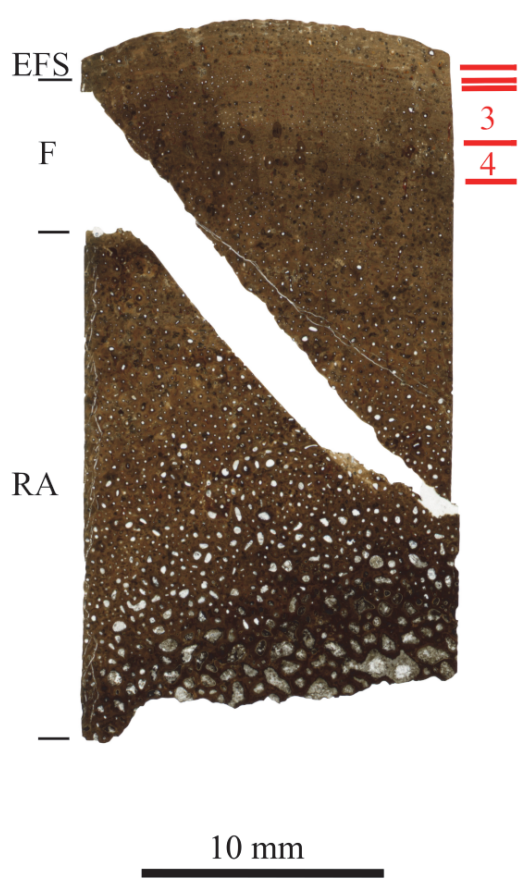

C

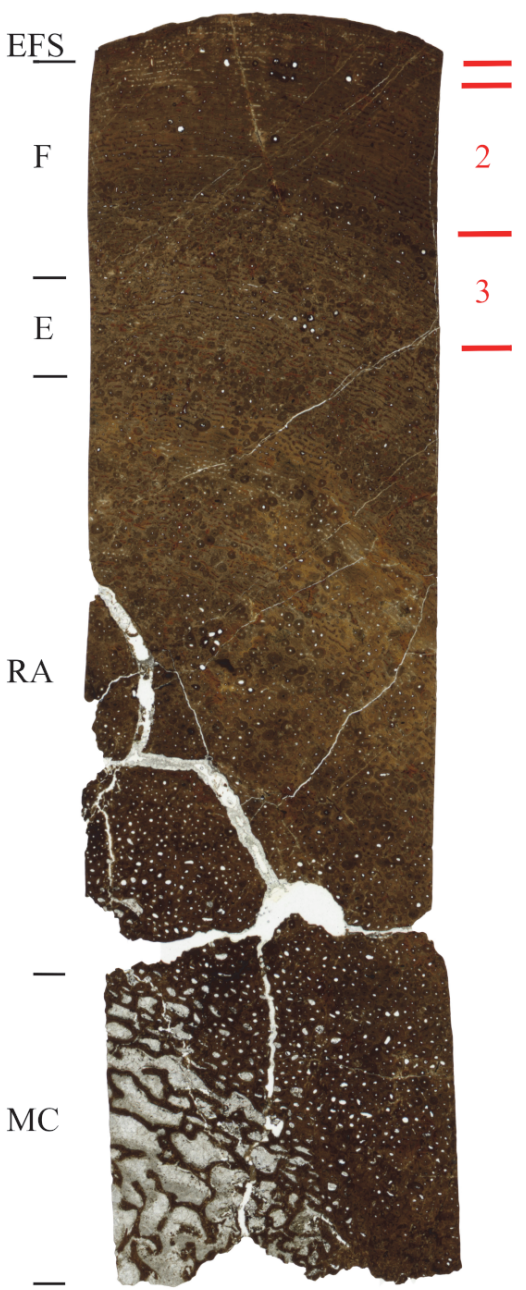

FIGURE 6. Images of all samples taken from SMA 0007 "XL". A, humerus (r). B, ulna (I). C, tibia (?). For all samples, the bone tissue types are indicated to the left, and the number and patterns of the visible growth cycles are indicated to the right. Abbreviations; E: Bone tissue type E, EFS: External fundamental system, F: Bone tissue type F, MC: Medullary cavity, RA: Remodeled area.

E, with remains of tissue type $D$ in the inner cortex (Figure 9C), indicating HOS 9. Thus, humeri SMA G46/87-1 and SMA G50/91-1 are individuals of BOS Sexual Maturity, and femur SMA G47/87-1 was a mature individual of BOS Adult I.

In both humerus SMA G46/87-1 and femur SMA G47/87-1, the remodeling degree is low, and some large, open secondary osteons of one generation can be seen (RS 1). Half of the cortex of humerus G50/91-1 is remodeled; yet, the secondary osteons are still large and relatively open. Only one generation of secondary osteons can be observed (RS 2). Numerous growth marks can be seen in both humeri, but no EFS (Table 1). Neither growth marks nor EFS are visible in the femur. The cyclicity of the two humeri can be correlated (Fig- ure $9 \mathrm{~A}$ and $9 \mathrm{~B}$ ). Humerus SMA G46/87-1 shows eight cycles, and humerus SMA G50/91-1 shows nine cycles. Note that humerus G50/91-1 may possess two more cycles in the inner part of the cortex, which can be observed as possible polish lines; however, due to resorption, these cannot be convincingly counted as cycles and are therefore not included.

SMA 0014 “Jacques", Apatosaurus louisae. This specimen consists of a semi-articulated hind limb (Figure 2). Table 1 lists all sampled bones from this specimen.

In general, the histology of all three bone samples is homogeneous. They all possess, in the outer half of the cortex, highly vascularized laminar fibrolamellar bone with wide vascular canals and 

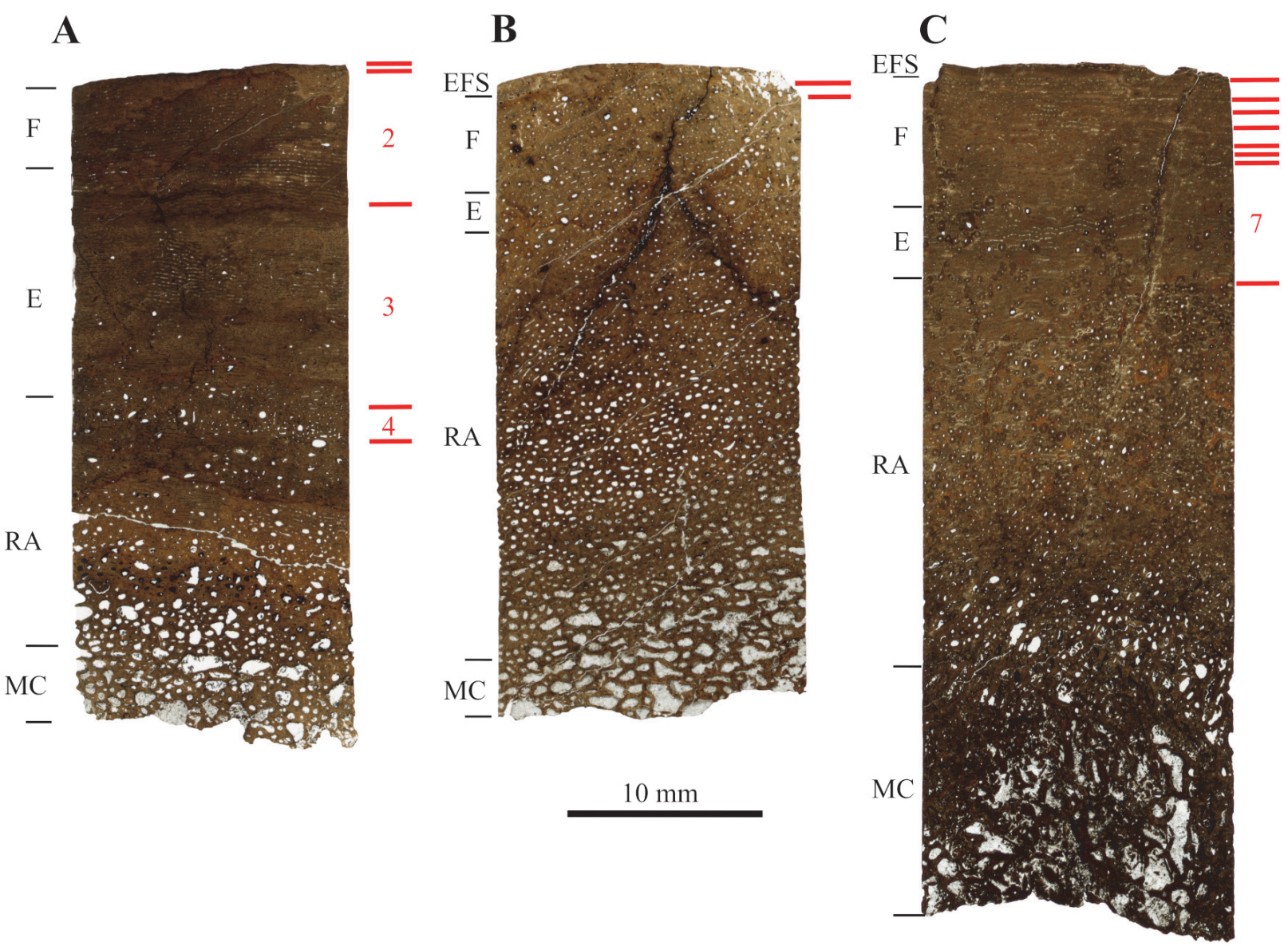

FIGURE 7. Images of all samples taken from SMA 0015 "David". A, femur (I). B, tibia (I). C, fibula (I). For all samples, the bone tissue types are indicated to the left, and the number and patterns of the visible growth cycles are indicated to the right. Abbreviations; E: Bone tissue type E, EFS: External fundamental system, F: Bone tissue type F, MC: Medullary cavity, RA: Remodeled area.

immature primary osteons. Numerous and clear growth marks are preserved in all three samples. Small differences can also be observed; the primary osteons in the tibia are wider than those seen in the femur and have a reticular orientation in some regions. When the anterior and posterior sections of the femur are compared, the thickness of the cortex is seen to vary within this bone (as can also be seen in SMA 0011 "Max"). Thus, the anterior part of the cortex is thicker than the posterior one. However, the histology of both sections is identical, and the ratio of remodeled cortex is comparable (Table 1, Figure 11A, and 11B). In the anterior section of the femur, a large and circular structure reminiscent of pathological bone tissue is observable (Figure 12). Also, in many cycles, bone tissue with unorganized vascular canal orientation occurs throughout the primary cortex of "Jacques" tibia and femur (Figure 12). This unorganized bone tissue is due to faster growth directly following bands of slower growth, and leads to a very distinctive cyclicity compared to all other samples taken from the Howe-Stephens and Howe Scott quarries.

Both the anterior and posterior samples of the femur are mainly formed by bone tissue type $E$, with tissue type $D$ remaining in the inner cortex (Figure $11 \mathrm{~A}$ and 11B). This corresponds to HOS 9 and BOS Adult I. The anterior section of the femur shows slightly more advanced bone tissue and is therefore on the verge of becoming HOS 10. The tibia also possesses mainly type $E$ bone tissue, with tissue type $\mathrm{F}$ laid down in the outermost cortex (Figure 11C), leading to HOS 10 and BOS Adult I to Adult II. SMA 0014 thus was a mature individual of BOS Adult I to Adult II.

All the bones that were sampled from SMA 0014 "Jacques" are partially remodeled. The bone of the anterior section of the femur is slightly more 


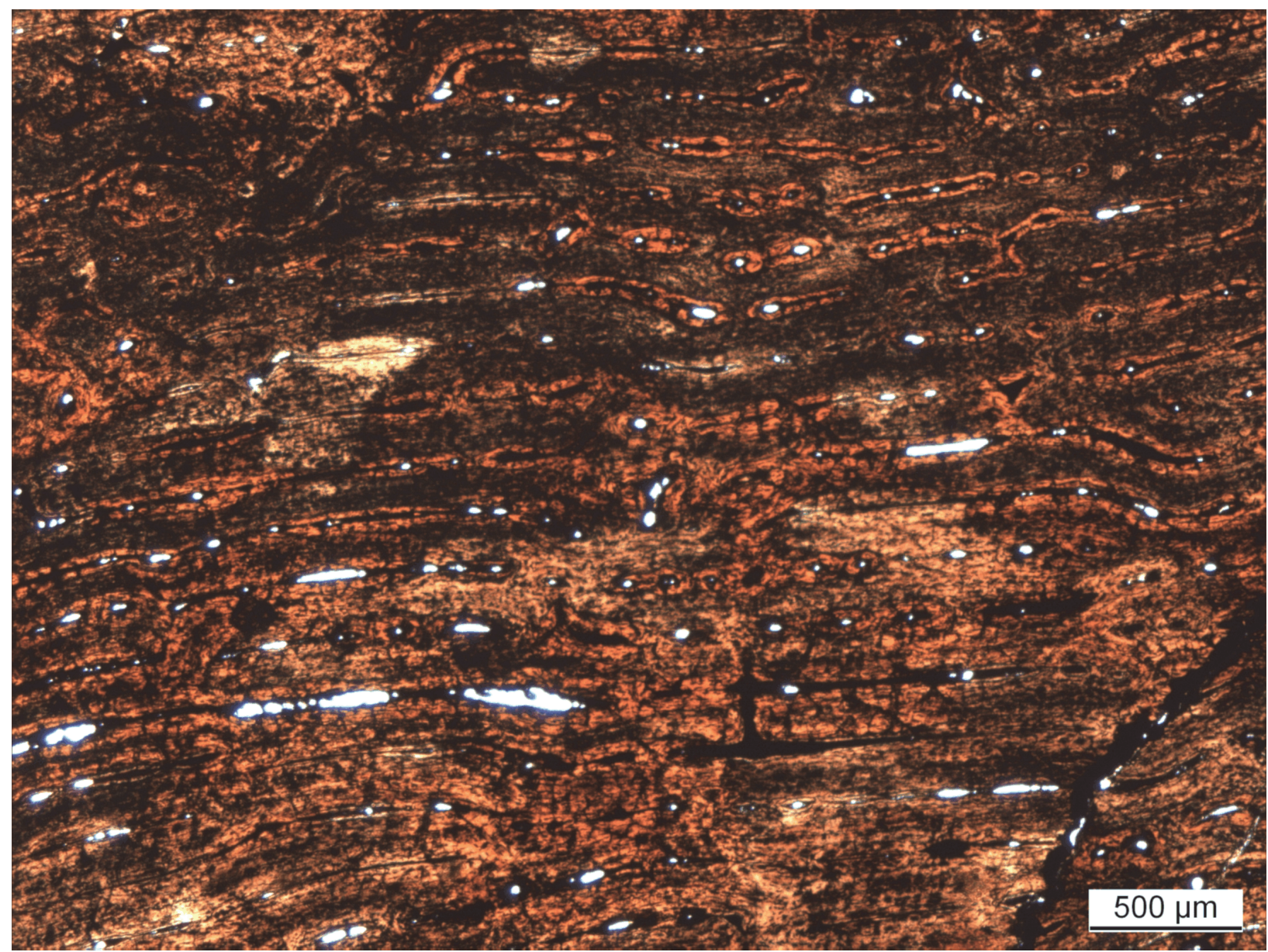

FIGURE 8. View of outer cortex of SMA 0015 "David" femur with the characteristic orange, diagenetic coloration which can be observed in all the SMA 0015 "David" samples. This image was taken from the outer cortex of SMA 0015 "David" femur.

remodeled $(50 \%)$ than the posterior section (45\%). In both samples, one and two generations of secondary osteons are present in the deep cortex (RS 3 ). The rate of remodeling of the tibia is slightly higher than that of the femur, such that $60 \%$ of the cortex is remodeled, with up to two generations of secondary osteons (RS 4).

As stated earlier, in both the femur and the tibia, growth marks are well preserved and distinct, which constitutes a unique feature of SMA 0014 "Jacques" compared to other specimens in this study. Both the anterior and posterior femur sections show 18 cycles, and the tibia possesses nine cycles. The pattern that these cycles form can be correlated in all three samples (Figure 11).

SMA 0011 "Max", Galeamopus sp. This specimen represents a nearly complete and largely articulated skeleton of Galeamopus (Figure 2; Tschopp et al., 2015). Table 1 lists all sampled bones from this specimen.
In general, the histology of all sampled bones from the fore- and hindlimbs is consistent. The primary fibrolamellar bone tissue is laminar with wide primary osteons. Growth marks are well preserved in these samples. Some small differences however, can be observed between the skeletal elements.

In both humeri (Figure 13A and 13B), three bands of wider primary osteons are visible in the middle cortex, which indicate periods of faster growth. These bands represent subtle modulations of growth rate. These modulations are also present in both the anterior and posterior sections of the left femur, but cannot be seen in the zeugopodial elements. These modulations are probably expressed as LAGs in the zeugopodial elements. This is possibly due to faster growth of the humeri and femora. The ulna and radius are highly remodeled, and little of the primary cortical bone remains (Figure $13 \mathrm{C}$ and 13D). 
A

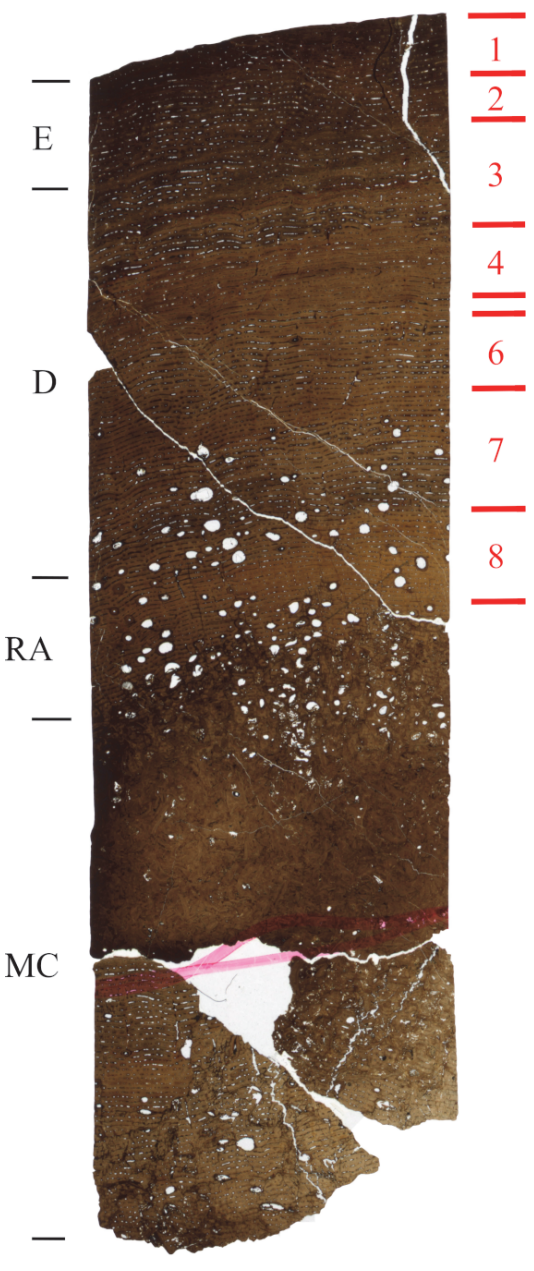

B

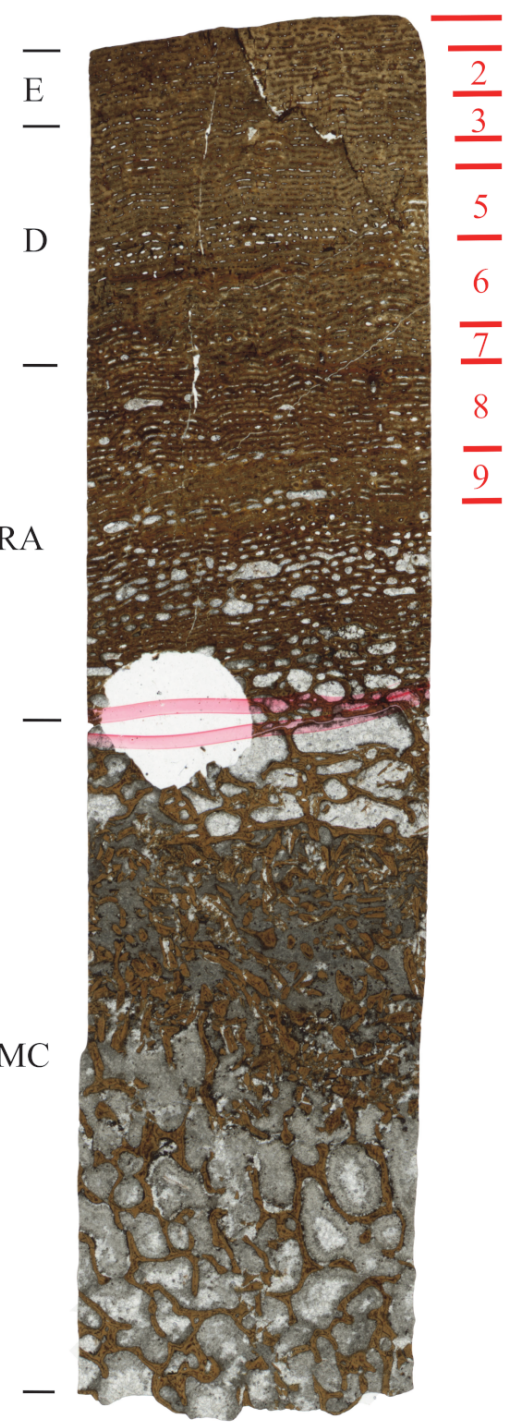

$\mathrm{C}$

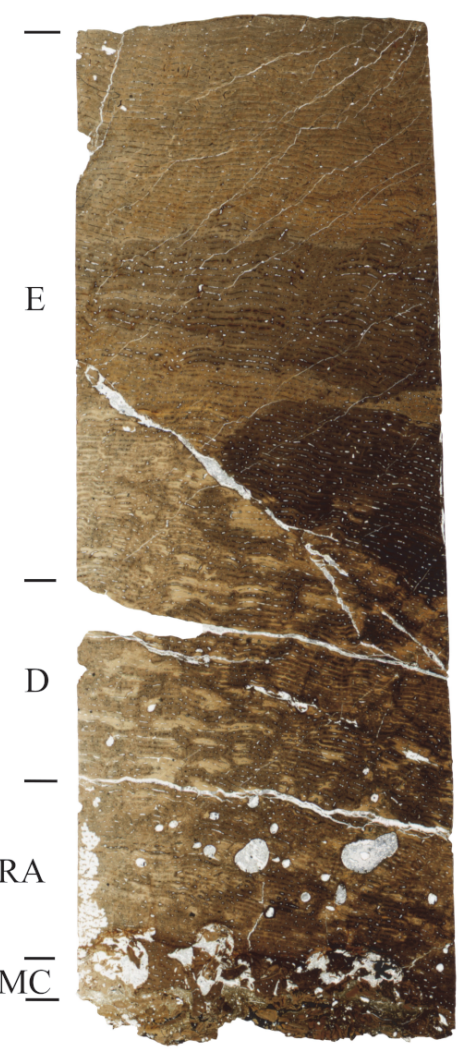

$10 \mathrm{~mm}$

FIGURE 9. Images of all samples taken from the isolated bones SMA G47/87-1, G47/87-1 and G50/91-1. A, SMA G46/87-1 humerus (I). B, SMA G50/91-1 humerus (r). C, SMA G47/87-1 femur (I). For all samples, the bone tissue types are indicated to the left, and the number and patterns of the visible growth cycles are indicated to the right. Abbreviations; D: Bone tissue type D, E: Bone tissue type E, MC: Medullary cavity, RA: Remodeled area.

When compared, the thickness of the cortex varies within the mid-diaphysis between the anterior and posterior sections of the left femur of SMA 0011 "Max" (Figure 14A and 14B). As in SMA 0014 "Jacques", the anterior femoral cortex is thicker than the posterior one. The histology of both sections is nonetheless similar, and the ratio of the remodeled cortex is comparable.

Both the humeri (Figure 13A and 13B) show primarily bone tissue type $D$, with bone tissue type E laid down in the outer cortex (Table 1). This indicates that both humeri are HOS 8 , corresponding to sexual maturity. Both ulna and radius possess mostly bone tissue type $\mathrm{E}$, with type $\mathrm{F}$ bone tissue laid down in the outermost cortex (Figure 13C and 13D). Ulna and radius thus represent HOS 10 and BOS Adult I to Adult II. The femur (Figure 14A and 14B), like both humeri, also consists primarily of bone tissue type $D$, with type $E$ laid down in the outer cortex (Table 1). This corresponds to HOS 8 and sexual maturity. The tibia and fibula sections consist mostly of bone tissue $E$, with type $D$ tissue remains preserved in the inner cortex (Figure 14C and 14D), so both tibia and fibula are HOS 9 and BOS Adult I. SMA 0011 thus was an individual of BOS Sexual Maturity to Adult II. 


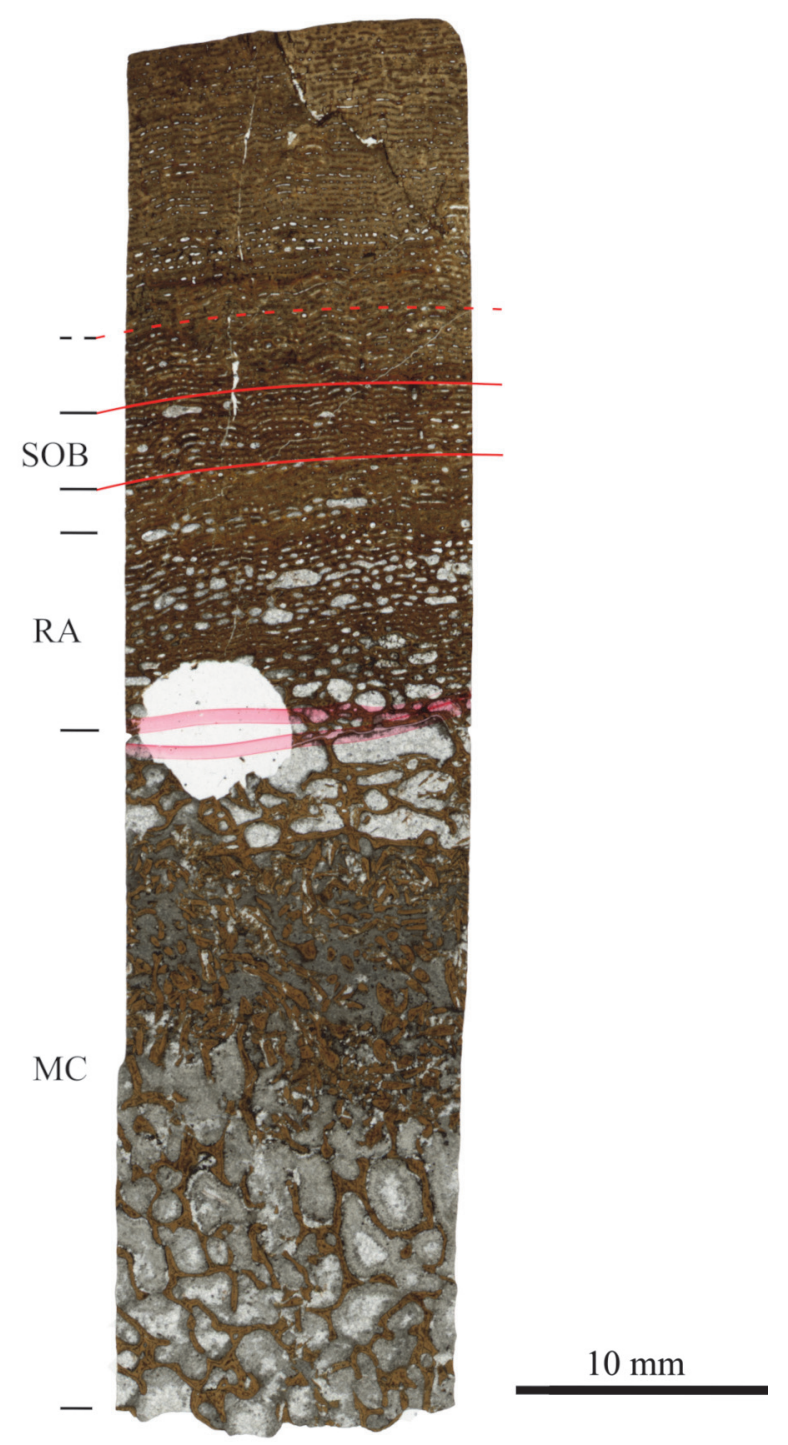

FIGURE 10. Band of secondary osteons in humerus SMA G50/91-1. The band of secondary osteons is located between the red lines. The area above the band of secondary osteons, marked by the dashed red line, consists of mainly primary bone with some isolated secondary osteons. In this area however, the density of secondary osteons is much lower than that seen in the secondary osteon band. Abbreviations; MC: Medullary cavity, RA: Remodeled area, SOB: Secondary osteon band.

In both humeri, remodeling has started, and secondary osteons affect up to $30 \%$ of the primary cortex. In these samples, only one generation of secondary osteons can be observed (RS 1). The ulna and radius are more heavily remodeled; approximately $65-70 \%$ of the primary cortex of both bones has been remodeled, mostly by one genera- tion, and rarely two generations of secondary osteons can be seen (RS 3). The femur has been remodeled up to $30 \%$ of the primary cortex, and only one generation of secondary osteons can be observed (RS 1). In both the tibia and fibula, remodeling has only progressed up to $50 \%$ of the primary cortices, and they show mostly one generation and rarely two generations of secondary osteons (RS 3).

Growth marks can be observed in all sampled bones (Table 1). When the growth mark record of both humeri is compared, a similar pattern is present (Figure 13A and 13B). We count in the right and left humeri 10 and eight cycles, respectively. However, this difference is probably due to the fact that the outer bone surface is missing in the left humerus. The radius contains 11 cycles and the ulna 10 cycles. The cyclicity of both the anterior and the posterior sections of the femur is similar, yet slight differences do occur, since the anterior section shows 13 cycles and the posterior section shows 11 cycles. The tibia of "Max" possesses nine cycles, and its fibula eight cycles. Femur SMA M16/12-3 shows primarily bone tissue type $F$ with remnants of bone tissue type $E$ in the inner cortex (Figure 14E), and is therefore HOS 11 and BOS Adult II. The primary cortex of femur SMA M16/123 is up to $65 \%$ remodeled, and therefore older than the SMA 0011 "Max" femur. Two generations of secondary osteons can be observed in SMA M16/ 12-3 (RS 3). The growth mark cyclicity of femur SMA M16/12-3 is difficult to determine due to the preservation of the specimen. However, two cycles can be observed. All SMA 0011 "Max" bones do not seem to possess an EFS, yet femur M16/12-3 does.

SMA 0084 "Rich", Diplodocinae sp. This specimen corresponds to three semi-articulated hindlimb bones. No other long bones from SMA 0084 "Rich" were excavated. Table 1 lists all sampled bones from this specimen.

Both the tibia and the fibula are heavily remodeled, and only the outermost part of the primary cortex is still visible (Figure $15 \mathrm{~A}$ and 15B). It is also interesting to note that some of the numerous secondary osteons preserve a large lumen in both elements, but more particularly in the fibula. Characteristic for these samples is the strong black diagenetic coloration, which cannot be observed in most of the other Howe-Stephens Quarry and Howe Scott Quarry samples (but in SMA 0087 "Chris", see below). Due to the heavy remodeling, the bone tissue type found in both bones is type $\mathrm{G}$, which correlates with HOS 13 and BOS Adult III. 
A

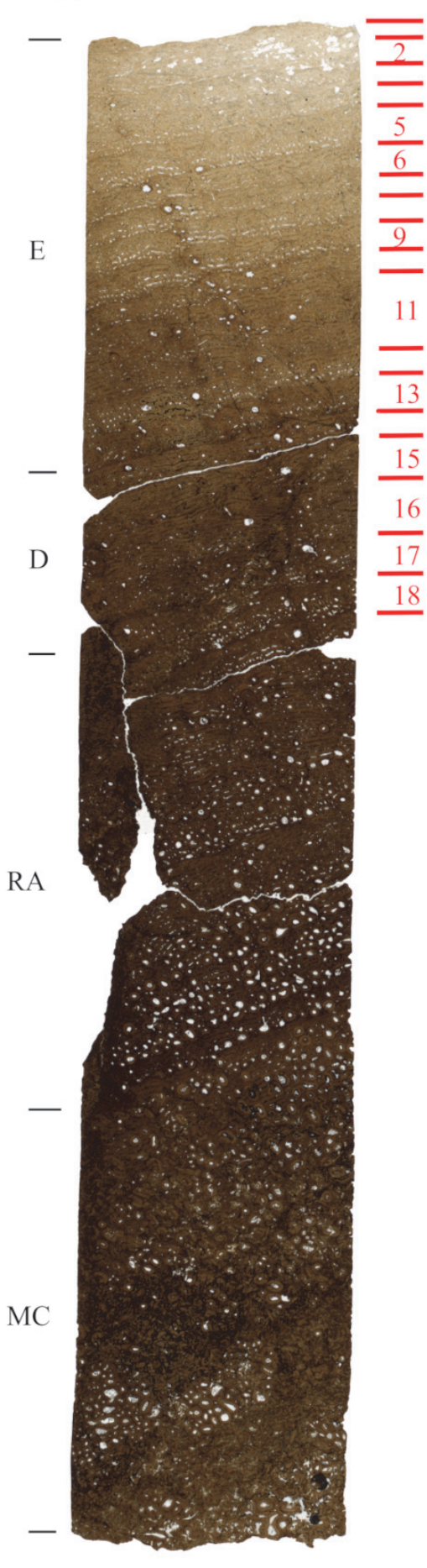

B

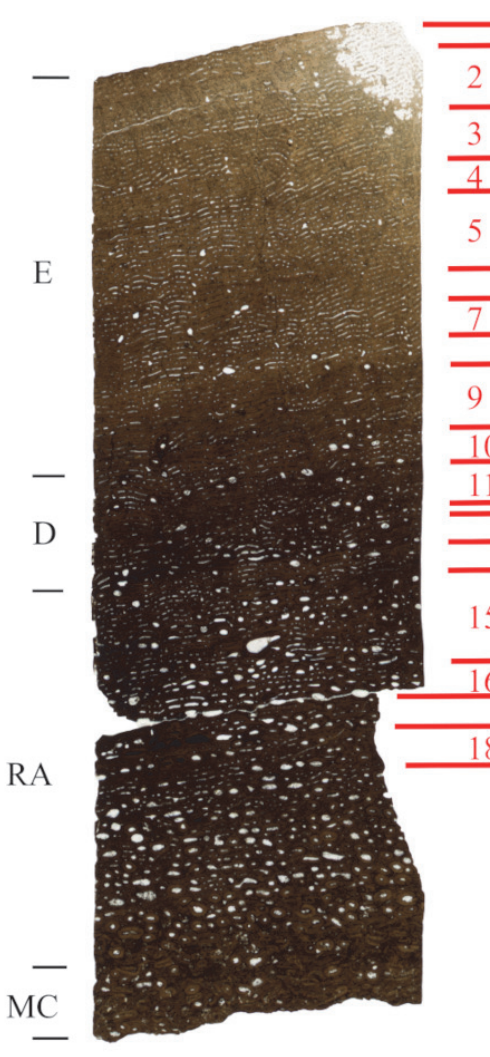

$10 \mathrm{~mm}$
C

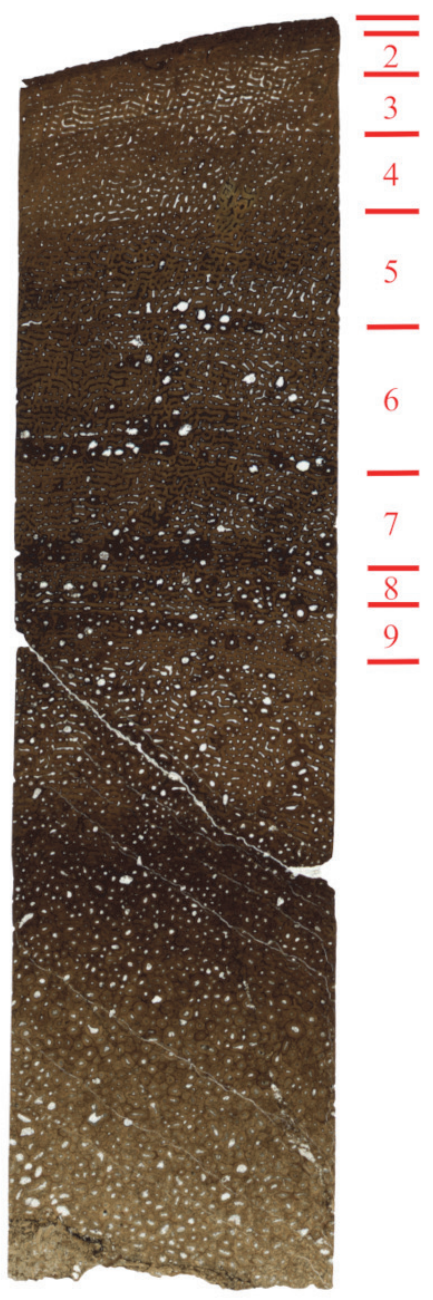

FIGURE 11. Images of all samples taken from SMA 0014 "Jacques". A, femur (r), drilled on the anterior side. B, femur $(r)$, drilled on the posterior side. C, tibia ( $r$ ). For all samples, the bone tissue types are indicated to the left, and the number and patterns of the visible growth cycles are indicated to the right. Abbreviations; D: Bone tissue type D, E: Bone tissue type E, F: Bone tissue type F, MC: Medullary cavity, RA: Remodeled area. 

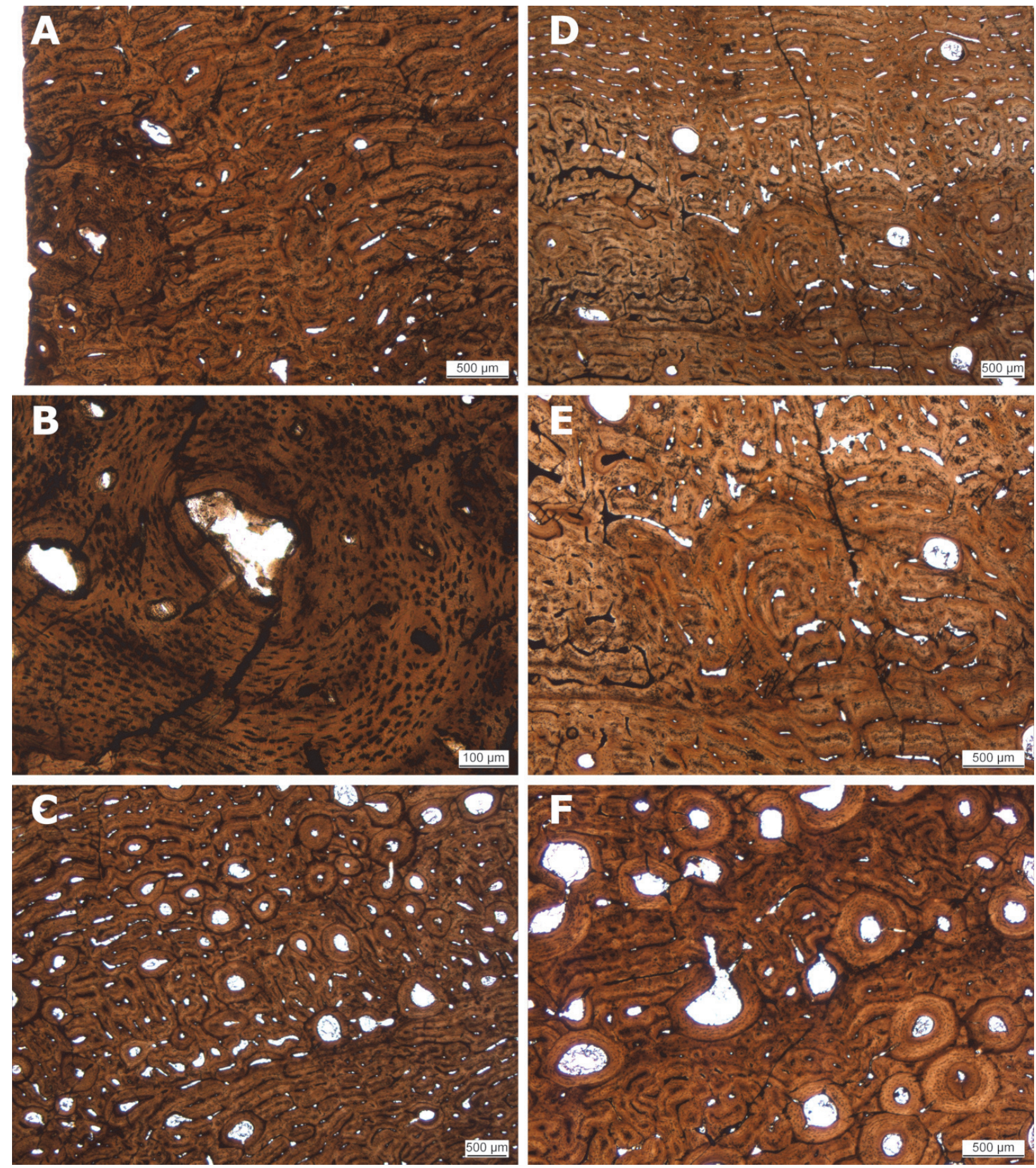

FIGURE 12. Several histological structures observed in the anterior section of the femur of SMA 0014 "Jacques". A, Large circular structure, which possesses clear circumferentially orientated vascular canals. B, Close-up of the circular structure and the vascular canals. C, D, F, Cycles which show unorganized bone tissue, and varying vascular canal orientations. E, Close-up of unorganized bone tissue cycle. Images taken under plane-polarized light. 
A

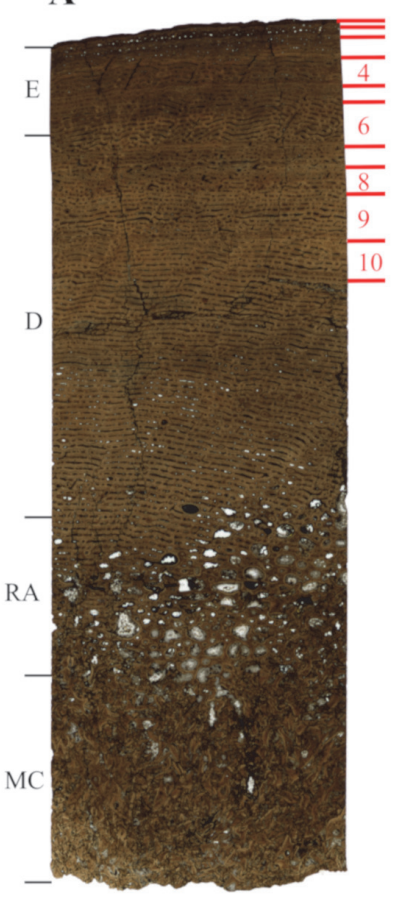

B

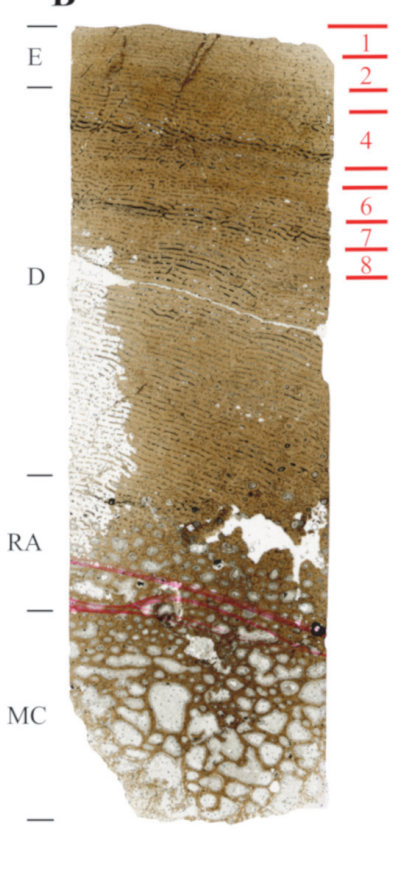

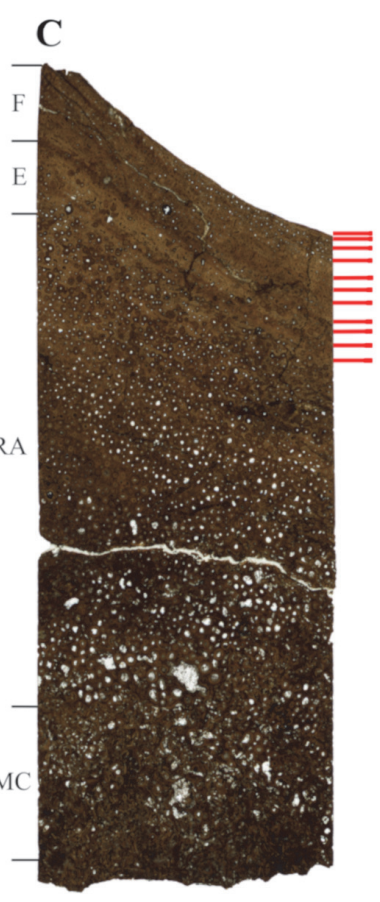

D

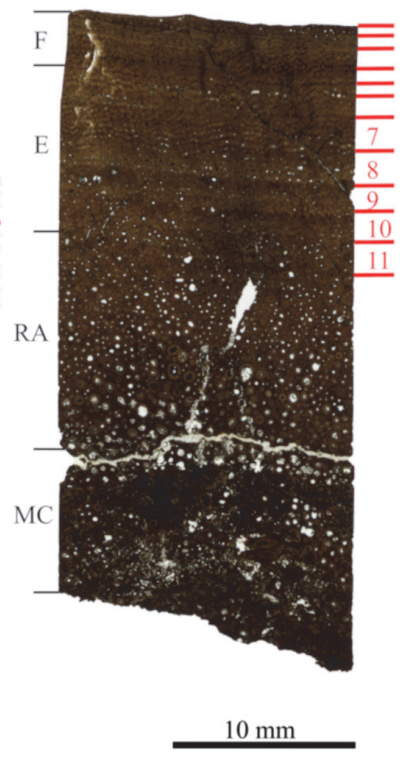

FIGURE 13. Images of all forelimb samples taken from SMA 0011 "Max". A, humerus (r). B, humerus (I). C, ulna (I). D, radius (I). For all samples, the bone tissue types are indicated to the left, and the number and patterns of the visible growth cycles are indicated to the right. Abbreviations; D: Bone tissue type D, E: Bone tissue type E, F: Bone tissue type F, MC: Medullary cavity, RA: Remodeled area.

Remodeling has progressed throughout the entire cortex and even into the EFS. Mostly two, but also three generations of secondary osteons can be found (RS 7). Thus, SMA 0084 was a mature individual of BOS Adult III.

No growth marks could be identified in the cortex of the fibula, apart from the EFS in the outermost cortex (Figure 15B), whereas the tibia possesses one cycle (Figure 15A). The tibia also shows a well-developed EFS. The number of LAGs in the EFS differs slightly between the tibia and the fibula of "Rich". This is probably due to the poorly preserved bone surface, leading to the loss of LAGs from the EFS. Also, the fibula of "Rich" shows an EFS which includes a cycle of slightly faster bone growth, which cannot be seen in the tibia (Figure 16A and 16B), which is possibly again due to the loss of the original bone surface.

SMA 0087 "Chris", Diplodocinae sp. This specimen corresponds to an articulated vertebral column with ribs and the right hindlimb. Table 1 lists all sampled bones from this specimen.

The femur still shows primary bone tissue with well-organized and wide circumferential primary osteons. In the outer cortex, LAGs are well preserved. Characteristic for the tibia and fibula is the strong black diagenetic coloration, which is also seen in the SMA 0084 "Rich" samples. Both the tibia and fibula are heavily remodeled, with some primary bone tissue remaining in the outermost zone of these bones. The femur consists primarily of bone tissue type $E$, with tissue type $F$ laid down in the outer cortex (Figure 17A). This represents HOS 10 (on the verge of becoming HOS 11) and BOS Adult I. The cortex of the tibia and fibula is comprised entirely of bone tissue type $G$ (Figure $17 \mathrm{~B}$ and $17 \mathrm{C}$ ), which therefore are assigned to HOS 13 and BOS Adult III. SMA 0087 thus was a mature individual of BOS Adult III.

The cortex of the femur of SMA 0087 "Chris" has been remodeled up to $50 \%$ by secondary osteons, which occur only as one generation (RS 2). In both the tibia and fibula, the entire cortex has been remodeled. The Haversian bone consists of two, sometimes three generations of secondary osteons (RS 7). As for the "Rich" specimen, numerous secondary osteons preserve a large lumen in both elements.

Growth marks are preserved in all three sampled bones in the form of an EFS (in all sections) and throughout the cortex of the femur (Table 1). The femur shows very good annual growth cycles; in total, six cycles could be identified. Two cycles can still be observed in the tibia, even though it is 

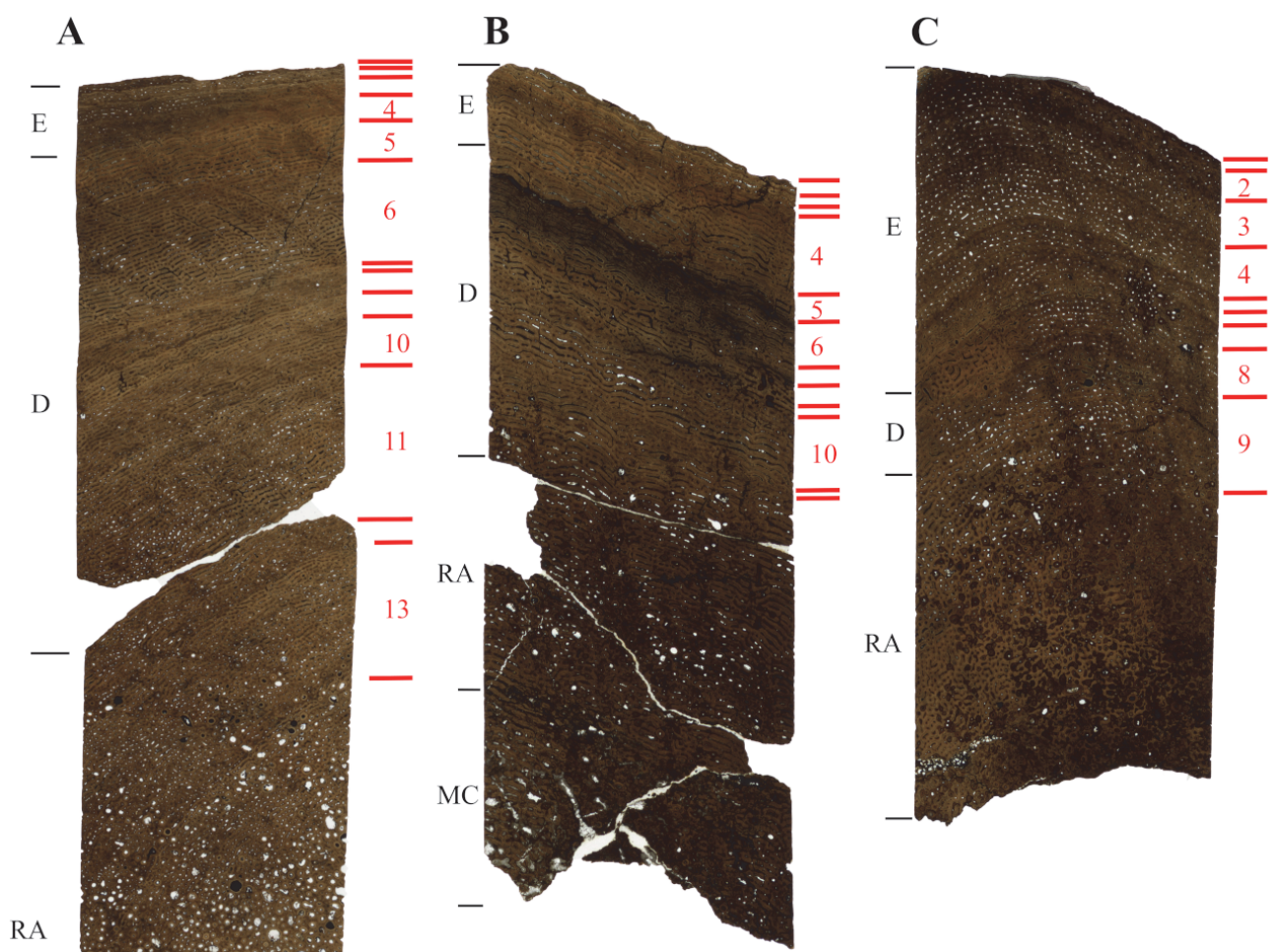

D

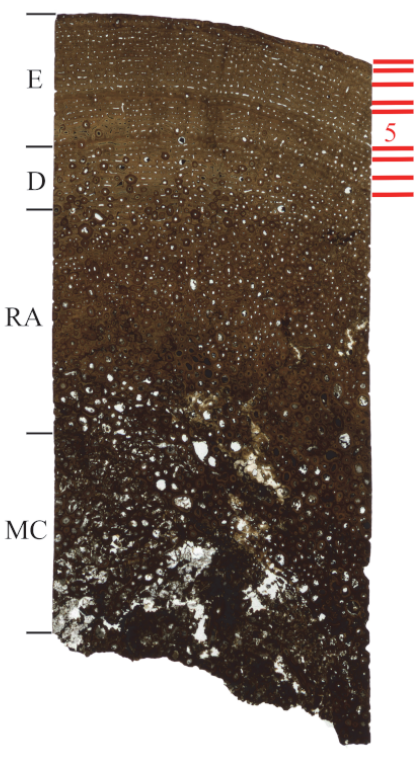

$\mathbf{E}$
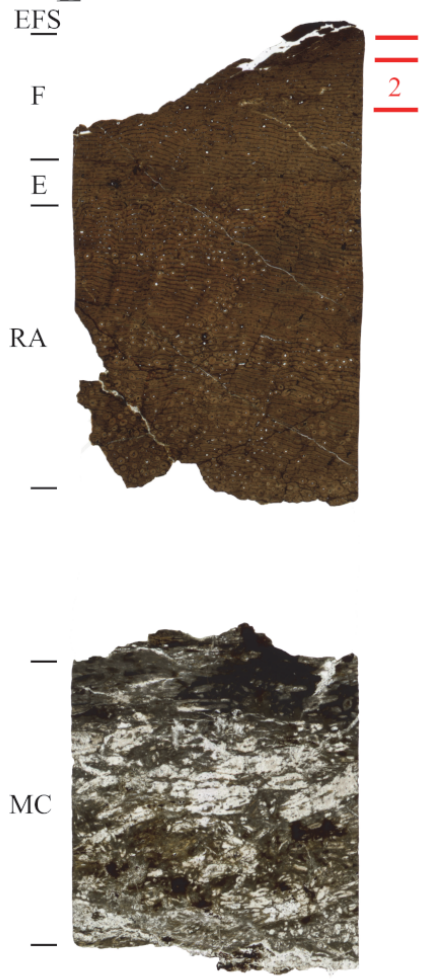

FIGURE 14. Images of all hindlimb samples taken from SMA 0011 "Max". A, femur (I), drilled on the anterior side. B, femur (I), drilled on the posterior side. C, tibia (I). D, fibula (I). E, SMA M16/12-3 femur (I). For all samples, the bone tissue types are indicated to the left, and the number and patterns of the visible growth cycles are indicated to the right. Abbreviations; D: Bone tissue type D, E: Bone tissue type E, EFS: External fundamental system, F: Bone tissue type F, MC: Medullary cavity, RA: Remodeled area. 

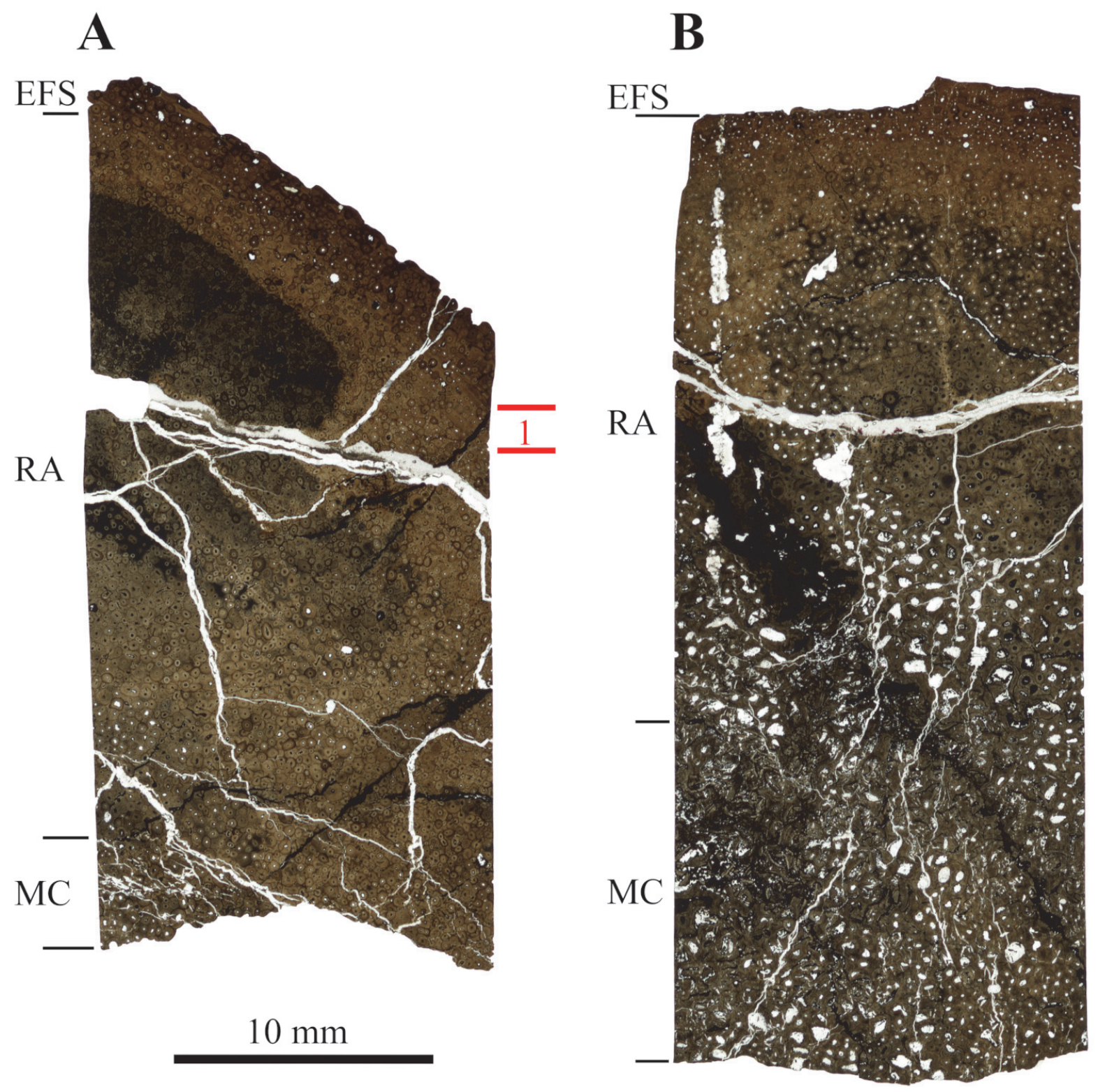

FIGURE 15. Images of both samples taken from SMA 0084 "Rich". A, tibia (I). B, fibula (I). For all samples, the bone tissue types are indicated to the left, and the number and patterns of the visible growth cycles are indicated to the right. Abbreviations; EFS: External fundamental system, MC: Medullary cavity, RA: Remodeled area.

highly remodeled, whereas the fibula shows none. The number of LAGs in the EFS of the tibia differs from those of the femur and the fibula. However, the original bone surfaces are not preserved (Figure $18 \mathrm{~A}$ and $18 \mathrm{C}$ ). In the EFS of all sections obtained from SMA 0087 "Chris", a single cycle of faster growth if present (Figure 18).

\section{DISCUSSION}

The previous assumptions of skeletal unity were based on observations in the field and during and after preparation by SMA staff, primarily author HJS and Dr. Ben Pabst. These consisted of the anatomical identification of the diverse skeletal elements and ruling out any skeletal duplicity, as well as preliminary taxonomic assignment of the putative skeletons and isolated bones and their plotting in quarry maps of the Howe Ranch quarries (see also Ayer, 2000). The taxonomic affinity of some of the specimens was then later revised by $E$. Tschopp (partially in Tschopp et al., 2015 and par- 

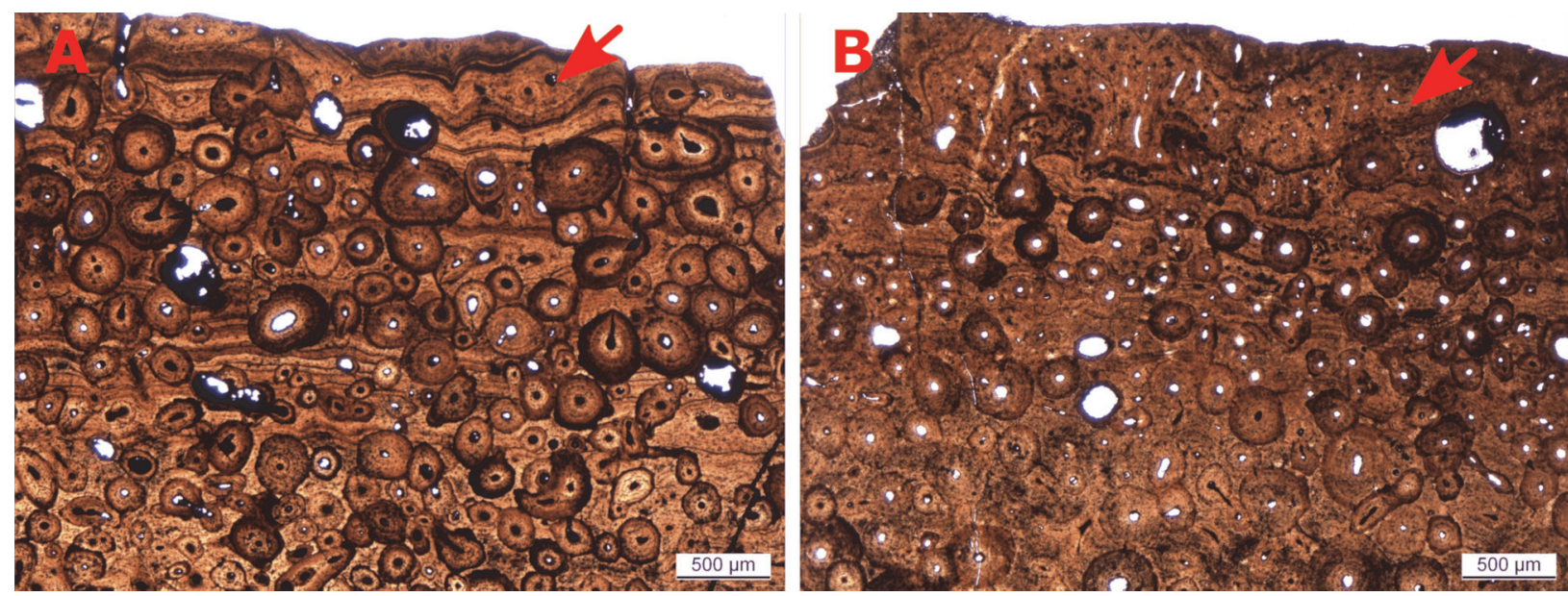

FIGURE 16. Detailed images of the EFS of both the SMA 0084 "Rich" samples. A, EFS of SMA 0084 "Rich" tibia, in which a cycle of faster growth is included (indicated by arrow). B, EFS of SMA 0084 "Rich" fibula, which also shows a cycle of faster growth (indicated by arrow). Images taken under plane-polarized light.

tially by pers. commun.). The taxonomic affinities are reported in the quarry maps in Figures 1 and 2.

\section{Comparison of Histological Evidence with the Quarry Map Hypotheses}

Howe-Stephens Quarry. Bones from three individuals and three isolated bones were sampled from the Howe-Stephens Quarry. The histological features of all the sampled bones of SMA 0002 "E.T." support skeletal unity for this specimen. Indeed, histological observations revealed that all elements belonged to an adult individual. Also, the outermost three cycles seen in both the femur and the tibia can be correlated. The assignment of the humerus to this taxon was slightly more difficult histologically, however. The humerus is more extensively remodeled than the tibia, which is odd since the humerus possesses a thicker cortex, and should therefore be less remodeled than the tibia. This feature, however, could possibly occur due to a pathology and is therefore possibly not age related. Also, the difference in the number of cycles is very striking, since the smaller tibia was expected to exhibit fewer preserved cycles than the femur due to more extensive remodeling of smaller bones (Padian et al., 2016 and references therein). This may be a special histological feature for this taxon. However, to test this hypothesis, more samples from this taxon need to be studied.

In case of SMA 0002 "E.T.", taphonomy provides clear evidence of skeletal unity since this specimen was preserved in complete articulation. The small, but mature specimen of Camarasaurus lewisi SMA 0002 is preserved with little crushing and is almost perfectly articulated (Figure 1; Ayer, 2000). Thus, there is no question as to the correlation of histological evidence and the quarry map. The histological ontogenetic stage of the long bones of this individual was assessed by Klein and Sander (2008). They show that the specimen is a fully grown, skeletally mature individual belonging to a small morph of Camarasaurus which is best assigned to C. lewisi (pers. commun. E. Tschopp).

Even though the skeletal elements assigned to Galeamopus sp. (?) SMA 0007 "XL" are scattered in the quarry and not directly articulated, they are preserved in sufficient proximity to suggest they are from the same individual (Figure 1). When all described histological characters are combined, similarities between the sampled bones of SMA 0007 can be identified. HOS and RS correlate with the length of the bones. Thus, the smallest sampled bone (in this case the ulna) is the most remodeled and possesses the highest HOS. However, slight inconsistencies between the samples also occur. The general histology and the presence, and number of the growth marks are slightly different, possibly due to the different degrees of remodeling. Histologically, the ulna differs from the humerus and the tibia in its small, longitudinal primary osteons. Possibly, this is the normal condition for Galeamopus ulnae, since the same can be observed in the ulna of Galeamopus sp. SMA 0011 "Max". To test this hypothesis, more ulnae of this taxon would have to be sampled and studied. Also, the cyclicity of the humerus and the ulna can be correlated. However, that of the tibia differs slightly. Yet, even with the slight differences taken into 

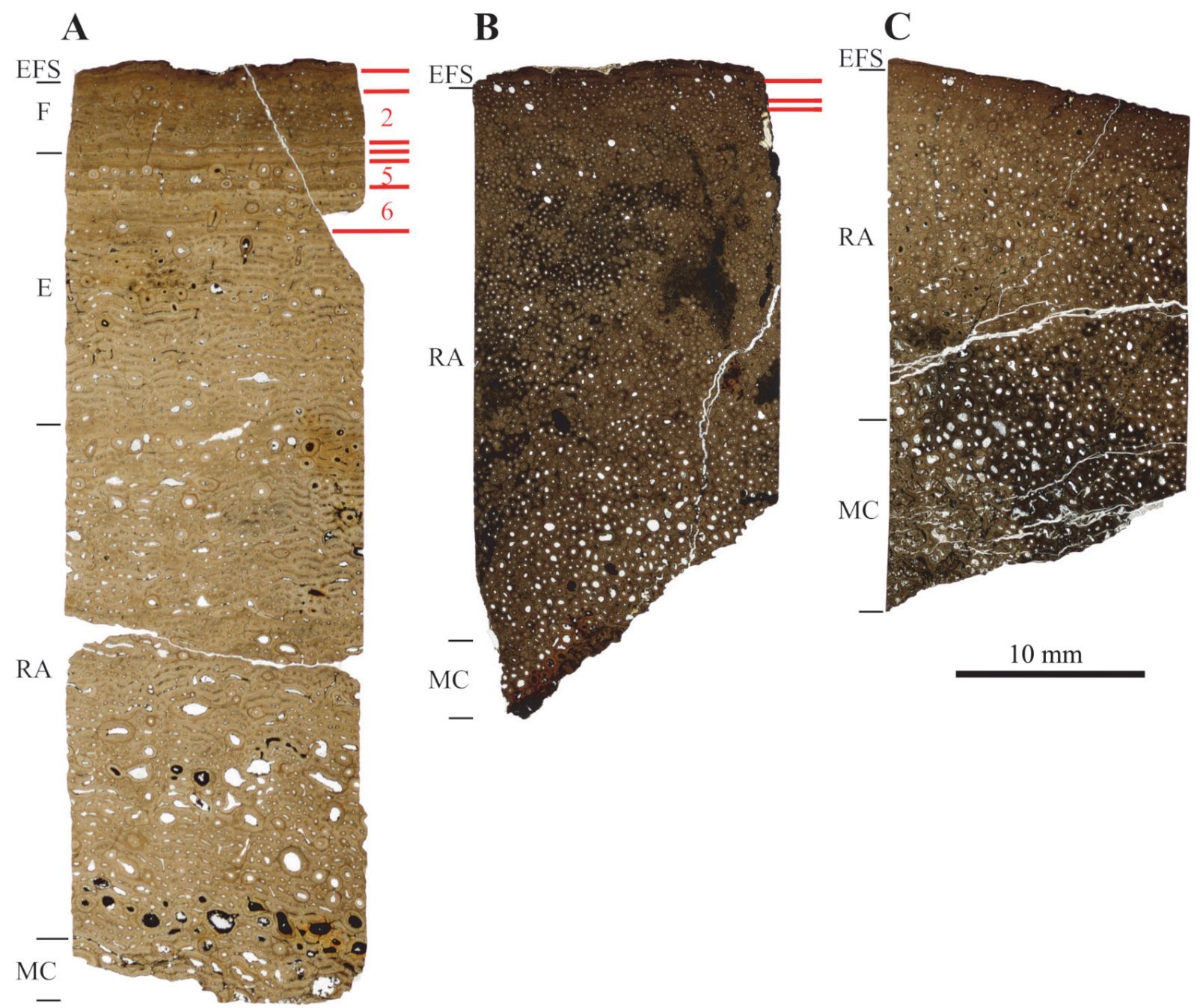

FIGURE 17. Images of all samples taken from SMA 0087 "Chris". A, femur (r). B, tibia (r). C, fibula (r). For all samples, the bone tissue types are indicated to the left, and the number and patterns of the visible growth cycles are indicated to the right. Abbreviations; E: Bone tissue type E, EFS: External fundamental system, F: Bone tissue type F, MC: Medullary cavity, RA: Remodeled area.

account, the hypothesis of skeletal unity could not be rejected for this specimen based on long bone histology.

Only one partial hindlimb was recovered (Figure 1) of Diplodocinae indet. SMA 0015 "David". SMA 0015 was found approximately $10 \mathrm{~m}$ north of specimens SMA 0007 "XL" and SMA 0002 "E.T." All histological features of the three skeletal elements of SMA 0015 "David" are consistent with an assignment to a single individual, but there is no evidence that this hindlimb belongs to any other skeleton in the quarry.

Three isolated bones, namely the humeri SMA G46/87-1 and SMA G50/91-1 and the femur SMA G47/87-1, were found north of SMA 0007 " $X L$ " in relatively close proximity to one another
(Figure 1). The histology of the three sampled bones is similar, but there are important differences. Some of the histological characters (HOS, growth marks, and cyclicity) for humeri SMA G46/ 87-1 and SMA G50/91-1 are roughly the same. Both humeri have approximately the same length, and they could represent both the right and left forelimb of the same individual. However, the general histology and degree of remodeling do not match. Based on the latter two characters, humerus SMA G46/87-1 and femur SMA G47/87-1 could pertain to one individual. Also note that the bones were found in close proximity to one another, which could indicate one individual. The hypothesis of skeletal unity with previously recognized skeletons is very difficult to support for these 

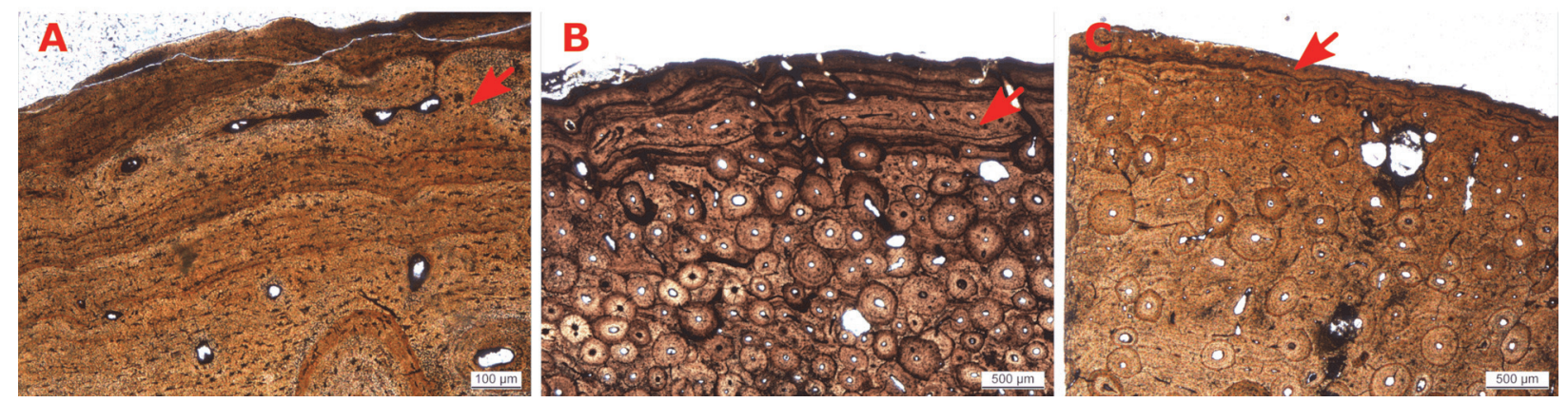

FIGURE 18. Detailed images of the EFS of the SMA 0087 "Chris" samples. A, EFS of SMA0087 "Chris" femur (r), in which a cycle of faster growth is included (indicated by arrow). B, EFS of SMA 0087 "Chris" tibia ( $r$ ), in which a cycle of faster growth is present (indicated by arrow). C, EFS of SMA 0087 "Chris" fibula ( $r$ ), which possesses a cycle of faster growth (indicated by arrow). Images taken under plane-polarized light.

bones, so it is more likely that these bones belong to different individuals, however, skeletal unity cannot entirely be rejected. When the histology and measurements of SMA G46/87-1, SMA G50/91-1, and SMA G47/87-1 are compared with the already identified individuals from the Howe-Stephens Quarry ("XL", "E.T.", and "David"), no match could be found.

Howe Scott Quarry. For the Howe Scott Quarry, samples were taken from four individuals. Only one leg was found of Apatosaurus louisae SMA 0014 "Jacques", and unlike in SMA 0015 "David", the bones were not clearly articulated, but associated (Figure 2). When all of the described characters of the samples are combined, skeletal unity is histologically supported for SMA 0014 "Jacques". The unique bone histology, with the well-differentiated growth cycles, the large vascular canals, and the general pattern seen in the HOS and RS indicate that both the femur and the tibia belong to one individual. Note that the ontogenetic difference between the anterior part of the femur and the tibia of "Jacques" is very small compared to other individuals. Histology and taphonomy show that the femur and the tibia belong to the same individual.

Galeamopus sp. SMA 0011 "Max" was found associated, and most of the bones were "piled-up" in the southeast corner of the Howe Scott Quarry (Figure 2). However, some bones were found articulated, e.g., the tibia and fibula. The sampled bones, therefore, were all found in close proximity to one another, which leads to the assumption of one individual. When all cyclicity evidence is combined, similar patterns result, suggesting that these bones belong to one individual. However, differences do occur due to the damage to the original bone surface, leading to the loss of some of the later cycles. Also, some slight differences of thick- ness can be observed in cycles. Nevertheless, histology suggests skeletal unity for all bones apart from SMA M16/12-3. Histology indicates that femur M16/12-3 does not belong to SMA 0011 "Max" because it possesses a higher HOS. Also, the pattern of cyclicity and the possible presence of an EFS are clear indications that this bone does not belong to individual "Max".

Due to an inaccuracy in the recorded grid coordinates for this bone, the location of femur SMA M16/12-3 could not be clearly identified on the quarry map. Personal communication with Dr. Ben Pabst indicates that femur SMA M16/12-3 is most likely the femur of individual "Willi" (Figure 2), but this cannot be tested in this study, since "Willi" could not be sampled.

The histology of the sampled bones of Diplodocinae sp. SMA 0084 "Rich" indicates that the sampled bones belong to the same, ontogenetically old individual. The similarity of the described characters of the tibia and fibula from SMA 0084 "Rich" is striking, although slight differences do occur. Field observations, on the other hand, give a clue to skeletal unity, since the leg of SMA 0084 "Rich" was found partially articulated. So by combining histological characters and taphonomy, skeletal unity can be proven for these samples.

The femur, tibia, and fibula of Diplodocinae sp. SMA 0087 "Chris" was sampled, and their histology indicates skeletal unity. The slight differences are due to the heavier remodeling of the smaller bones owing to their thinner cortex. Thus, even when these differences are considered, skeletal unity can still be assumed. Since SMA 0087 "Chris" is a partially articulated, posterior skeleton with a well-articulated hindlimb, histology matches the quarry map evidence. 
When the bones from Diplodocinae sp. SMA 0084 "Rich" and Diplodocinae sp. SMA 0087 "Chris" are compared, the similarity between the lower limb bone histology and measurements is striking. Many histological characters are similar in the tibiae and fibulae of both individuals, which suggest that these bones belong to the same individual. Also, the histological preservation of both tibiae and fibulae provide evidence for skeletal unity, since in all these bones, a strong black diagenetic coloration is present, which cannot be observed in any other bone from this quarry (Figures 15 and 17). Finally, the lengths of the lower limb bones from both "Rich" and "Chris" match, providing further support of skeletal unity. To accumulate additional evidence for this hypothesis of skeletal unity of SMA 0084 "Rich" and SMA 0087 "Chris", bones such as the femur from SMA 0084 "Rich" and several bones from SMA "Christina" could be sampled. This was not done for this study, since the femora of the "Rich" and the "Christina" specimens were not accessible at the time of sampling. "Christina" is a partially articulated specimen from which only the anterior part of the skeleton is preserved (Figure 2). Indeed, based on the quarry map, SMA "Christina" and SMA 0087 "Chris" can be suspected to be one individual.

To summarize, for almost all named specimens, a consensus between the assignment of individuals in the field and the histological assignment can be observed. However, this study shows that some bones were not assigned correctly, such as SMA M16/12-3, which does not match with individual SMA 0011 "Max" to which it was initially assigned. Also, the two separate individuals, SMA 0084 "Rich" and SMA 0087 "Chris", could be combined into a single individual. In general, the assignment of bones to individuals in the field worked well for the Howe-Stephens and Howe Scott quarries, but bone histology provided an independent test of assignment and resulted in a new match.

The method devised in this study presents a way to test skeletal unity for sauropod dinosaur skeletons and can be used for future specimenlevel phylogenetic analyses (Tschopp et al., 2015) and assessment of completeness metrics in sauropods (Mannion and Upchurch, 2010).

Features of histological preservation, i.e., diagenesis of the bones, can provide extra information on possible skeletal unity, as observed in the case of SMA 0015 "David", SMA 0084 "Rich", and SMA 0087 "Chris". Possibly informative features are the diagenetic infilling of the pore space in trabecular bone by calcite and other minerals as well as diagenetic coloration of bone tissue as observed in thin section. However, it is not clear why bones from a single quarry should have different diagenetic histories without evidence for reworking.

A problem that may arise when using this method is when multiple individuals show the same ontogenetic age, which could be possible when a catastrophic mass mortality of a social group occurred. Even when this situation occurs, the histology still shows a different life history for each individual, which indicates that the cyclicity of the growth marks and the general histology differ for each individual. Also, the taphonomy of the locality is important since this usually shows that most Morrison Formation localities are several mortality events and a distinction between the individuals that died in each event can be made.

Proportions were measured for all bones and then compared, to conduct a cross-scaling approach to further test skeletal unity. Cross-scaling has been extensively studied in tetrapods, including squamates and crocodilians (Blob, 2000), mammals (McMahon, 1975a, 1975b; Alexander et al., 1979; Biewener, 1983; Bertram and Biewener, 1990), and dinosaurs (Carrano, 1998, 2001; Christiansen, 1999; Kilbourne and Makovicky, 2010). However, due to extensive noise in the scaling results and circular reasoning, the cross-scaling approach could not be used in this study.

\section{Testing Taxonomic Affinity by Means of Bone Histology}

In our study, we observed clear differences between individuals that may be explained by phylogenetic affinity. Such differences are seen in bone tissue structure, orientation and density of vascular canals, development of growth marks, and patterns of remodeling. To test this hypothesis, bones of the same type (e.g., a humerus vs. another humerus) and HOS should be compared to exclude differences in histology based on ontogenetic age. We explored this approach based on the different individuals from the Howe-Stephens and Howe Scott quarries.

For individual SMA 0002 "E.T.", taxonomic affinity is clear due to the presence of its skull, which is assigned to Camarasaurus lewisi (pers. commun. E. Tschopp). Therefore, we can assume that its histology is representative of that Camarasaurus in general. SMA 0002 "E.T." possesses very narrow primary osteons, which are mostly laminar and longitudinal, and growth marks seem to be well preserved in this individual. Both the 
humerus and the tibia of "E.T." could not be compared to other humeri and tibiae in the sample for lack of correlative HOSs. Yet, the femur of "E.T." can be compared to SMA M16/12-3, which both shows HOS 11. SMA M16/12-3 possesses wider primary osteons that are mostly laminar, and growth marks are not as well preserved in this sample. These differences in histology may represent a difference in taxonomic affinity. However, since both were located in different quarries, an assignment to a specific individual is not possibly for SMA M16/12-3.

SMA 0007 "XL" possesses narrow and laminar primary osteons, and growth marks seem poorly preserved. For "XL", only the tibia (HOS 11) could be compared with the tibia of SMA 0015 "David". They show roughly the same histological features. According to these findings, SMA 0007 "XL" and SMA 0015 "David" could therefore possess the same taxonomic affinity, yet " $X L$ " is a Galeamopus sp. (?) and "David" a Diplodocinae indet. This would suggest that detecting taxonomic affinity based on histology cannot be applied at the genus level, but possibly on the family or higher clade level.

The primary osteons of SMA 0015 "David" are relatively narrow and mostly circumferential. The femur of "David" is assigned to HOS 10 and can be compared with the femur of SMA 0087 "Chris", which shows well-organized, wider, circumferential laminar primary osteons and well-preserved growth marks in the outer cortex. Based on the contrasting histologies, a different taxonomic affinity for these two individuals could be assumed. Yet, both SMA 0015 "David" (Diplodocinae indet.) and SMA 0087 "Chris" (Diplodocinae sp.) belong to the same family. This would indicate that a taxonomic assignment on the family level is not possible.

Both isolated humeri, SMA G46/87-1 and SMA G50/91-1, show narrow, circumferentially oriented primary osteons, and growth marks are poorly developed. The bones both show HOS 8, as do both humeri (left and right) of SMA 0011 "Max". However, "Max" differs in its denser vascularization with wide, circumferentially organized, laminar primary osteons from these isolated humeri. Growth marks seem to be better developed in "Max" as well. These differences in histology could then indicate different taxonomic affinity, yet all pertain to the same higher taxon, Diplodocinae (G46/87-1 and G50/91-1 are Diplodocinae indet., and "Max" is Galeamopus sp.). Here, taxonomic affinity cannot be detected at the family level, but possibly on the species-level. However, when isolated femur SMA
G47/87-1 (HOS 9) is compared to the femur of SMA 0014 "Jacques" (also HOS 9), clear differences in the density and orientation of the primary osteons and distinctive development of growth marks (distinctive in "Jacques") can be observed. Thus assignment at higher clade level (Diplodocidae) appears possible, since SMA G47/87-1 is a Diplodocinae indet. and "Jacques" is an Apatosaurus louisae. In the case of both SMA 0007 "XL" and SMA 0011 "Max", both of which are Galeamopus sp., histology differs in possible conspecifics, even taking into consideration that " $\mathrm{XL}$ " is older and possesses a different HOS. Taxonomic affinity of the tibiae and fibulae of SMA 0084 "Rich" and SMA 0087 "Chris" is difficult to determine by means of histology due to the heavily remodeled cortex. Thus any potential taxonomic signal in the histology of the sampled sauropod long bones from the Howe-Stephens and Howe Scott quarries is blurred by the ontogenetic signal.

\section{CONCLUSIONS}

The Morrison Formation is well known for its abundance and good preservation of sauropod dinosaurs (Figure 19). A problem that occurs when working on sauropod finds from mass accumulations of sauropod bones in the Morrison Formation is that the assignment of bones to individuals is difficult due the undiagnostic morphology, particularly of long bones, and unclear taphonomy, i.e., ambiguous patterns of association and articulation. This situation is reflected in mounted sauropod skeletons in museums, which are mostly composite skeletons. To correctly assign bones to individuals used in mounts to ensure that future anatomical, systematic, and phylogenetic studies and completeness assessments are accurate, we developed an approach in this study where skeletal unity can be histologically tested. We do this by means of several histological characters, such as histological ontogenetic stages (HOS), annual cyclicity, growth marks, rate of remodeling, and the number of generations of secondary osteons. In general, bones of the same individual and roughly same length, possess the same HOS, the same rate of remodeling, and the cyclicity and growth marks can be correlated. Note that smaller bones such as the zeugopodial elements show a higher HOS then the stylopodial elements. Important, however, is that characters such as morphology and taphonomy need to be included as well to give an accurate outcome as to skeletal unity since histology by itself does not provide a completely unequivocal outcome. 


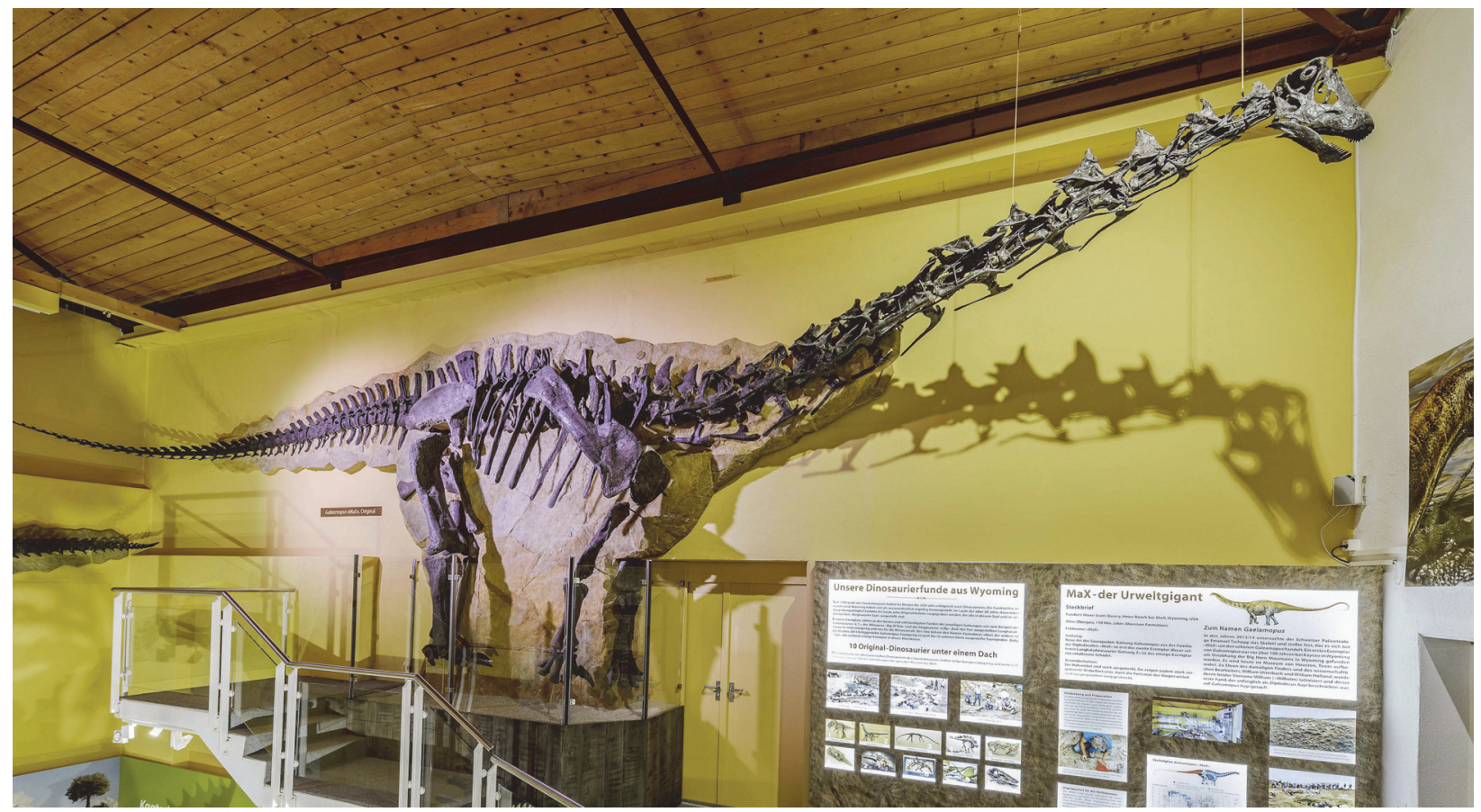

FIGURE 19. Mounted skeleton of Galeamopus sp. SMA 0011 "Max" from Howe Scott Quarry (Howe Ranch, Wyoming, USA) on display at Sauriermuseum Aathal, Switzerland. Length of femur is $1490 \mathrm{~mm}$. Image credit: Urs Möckli, Sauriermuseum Aathal.

In general, after testing the hypothesis of skeletal unity on SMA 0002 "E.T." (of which the skeletal unity was clear due to full articulation), four types of results were acquired. The first is a consensus between the field assignment and the histological assignment (e.g., SMA 0014 "Jacques" and SMA 0015 "David"). The second type is proving that a bone does not belong to the individual it was initially assigned to (e.g., SMA M16/12-3). The third type of result is combining two existing individuals into one (e.g., SMA 0084 "Rich" and SMA 0087 "Chris"). The last type of result, which did not occur with certainty in this study, is matching isolated bones to an already existing individual or creating a new individual (possibly SMA G46/87-1, SMA G47/ 87-1, and SMA G50/91-1). Note that the approach presented in this study does not provide a $100 \%$ conclusive outcome, but it is nonetheless the most rigorous assessment of skeletal unity to date. Future work to further enhance the method should involve testing skeletal unity based on bone diagenesis and on cross-scaling of limb bones.

\section{ACKNOWLEDGEMENTS}

The authors would like to thank the Sauriermuseum Aathal (Aathal, Switzerland) and T. Bolliger for collaboration and granting us access to the Howe-Stephens Quarry and Howe Scott Quarry material and for providing detailed quarry maps of the locality. Furthermore, we would like to thank B. Papst and R. Lilich of the SMA for providing detailed information about the Howe-Stephens Quarry and Howe Scott Quarry specimens and for their support during the sampling. All the members of the former DFG Research Unit "Biology of the Sauropod Dinosaurs" are greatly acknowledged for inspiring communication, especially J. Mitchell and K. Waskow for fruitful discussion, and J. Lallensack for his assistance with Inkscape. We greatly acknowledge O. Dülfer from the Institute of Geosciences (University of Bonn) for preparing the thin sections. The authors would like to thank the senior editor and associate editors of the journal as well as the anonymous reviewers. 


\section{REFERENCES}

Alexander, R.M., Jayes, A.S., Maloiy, G.M.O., and Wathuta, E.M. 1979. Allometry of the limb bones of mammals from shrews (Sorex) to elephant (Loxodonta). Journal of Zoology, 189:305-314.

Ayer, J. 2000. The Howe Ranch Dinosaurs. Sauriermuseum Aathal, Aathal.

Barrett, P.M. and Upchurch, P. 2005. Sauropodomorph diversity through time, p. 125-156. In Curry Rogers, K.A. and Wilson, J.A. (eds.), The Sauropods: Evolution and Paleobiology. University of California Press, Berkeley.

Bertram, J.E.A. and Biewener, A.A. 1990. Differential scaling of the long bones in the terrestrial Carnivora and other mammals. Journal of Morphology, 204:157-169.

Biewener, A.A. 1983. Allometry of quadrupedal locomotion: the scaling of duty factor, bone curvature, and limb orientation to body size. Journal of Experimental Biology, 105:147-171.

Blob, R.W. 2000. Interspecific scaling of the hindlimb skeleton in lizards, crocodilians, felids, and canids: does limb bone shape correlate with limb posture? Journal of Zoology, 250:507-531. https://doi.org/10.1111/j.1469-7998.2000.tb00793.x

Breithaupt, B.H. 1997. Howe Quarry, p. 355-356. In Currie, P.J. and Padian, K. (eds.), Encyclopedia of Dinosaurs. Academic Press, San Diego.

Brown, B. 1935. The American Museum Sinclair Expedition 1934. Natural History, 35:438.

Carballido, J.L., Scheil, M., Knötschke, N., and Sander, P.M. 2020. The appendicular skeleton of the dwarf macronarian sauropod Europasaurus holgeri from the Late Jurassic of Germany and a re-evaluation of its systematic affinities. Journal of Systematic Palaeontology, 18(9):739-781. https://doi.org/10.1080/14772019.2019.1683770

Carrano, M.T. 1998. The evolution of dinosaur locomotion: functional morphology, biomechanics, and modern analogs. Unpublished PhD Thesis, University of Chicago, Chicago, Illinois, USA.

Carrano, M.T. 2001. Implications of limb bone scaling, curvature and eccentricity in mammals and non-avian dinosaurs. Journal of Zoology, 25:41-55. https://doi.org/10.1017/S0952836901000541

Castanet, J., Francillon-Vieillot, H., Meunier, F.J., and de Ricqlès, A. 1993. Bone and individual aging, p. 245-283. In Hall, B.K. (ed.), Bone Volume 7: Bone Growth. CRC Press, Boca Raton.

Castanet, J. 1994. Age estimation and longevity in reptiles. Gerontology, 40:174-192.

Chinsamy, A. 1993. Bone histology and growth trajectory of the prosauropod dinosaur Massospondylus carinatus (Owen). Modern Geology, 18:319-329.

Christiansen, P. 1999. Long bone scaling and limb posture in non-avian theropods: evidence for differential limb allometry. Journal of Vertebrate Paleontology, 19:666-680. https://doi.org/10.1080/02724634.1999.10011180

Curry, K.A. 1999. Ontogenetic histology of Apatosaurus (Dinosauria: Sauropoda): new insights on growth rates and longevity. Journal of Vertebrate Paleontology, 19(4):654-665. https://doi.org/10.1080/02724634.1999.10011179

Curry Rogers, K. and Wilson, J.A. 2005. The Sauropods. Evolution and Paleobiology. University of California Press, Berkeley.

Erickson, G. M. 2005. Assessing dinosaur growth patterns: a microscopic revolution. Trends in Ecology and Evolution, 20:677-684. https://doi.org/10.1016/j.tree.2005.08.012

Erickson, G.M. 2014. On dinosaur growth. Annual Review of Earth and Planetary Sciences, 42:675-697. https://doi.org/10.1146/annurev-earth-060313-054858

Francillon-Vieillot, H., de Buffrénil, V., Castanet, J., Géraudie, J., Meunier, F.J., Sire, J.Y., Zylberberg, L., and de Ricqlès, A. 1990. Microstructure and mineralization of vertebrate skeletal tissues, p. 471-530. In Carter, J.G. (ed.), Skeletal Biomineralization: Patterns, Processes and Evolutionary Trends. Volume 1. Van Nostrand Reinhold, New York.

Gee, C.T. 2010. Plants in Mesozoic Time: Morphological Innovations, Phylogeny, Ecosystems. Indiana University Press, Bloomington and Indianapolis.

Griebeler, E. M., Klein, N., and Sander, P.M. 2013. Aging, maturation and growth of sauropodomorph dinosaurs as deduced from growth curves using long bone histological data: an assessment of methodological constraints and solutions. PLoS ONE, 8(6):e67012. 
Ikejiri, T. 2002. Biostratigraphic and geographic distribution of Camarasaurus (Dinosauria, Sauropoda) from the Morrison Formation. Geological Society of America Abstracts with Programs, 34(6):425.

Ikejiri, T., Tidwell, V., and Trexler, D.L. 2005. New adult specimens of Camarasaurus lentus highlight ontogenetic variation within the species, p. 154-179. In Tidwell, V. and Carpenter, V. (eds.), Thunder-Lizards. The Sauropodomorph Dinosaurs. Indiana University Press, Bloomington.

Kilbourne, B.M. and Makovicky, P.J. 2010. Limb bone allometry during postnatal ontogeny in non-avian dinosaurs. Journal of Anatomy, 217:135-152. https://doi.org/10.1111/j.1469-7580.2010.01253.x

Klein, N. and Sander, P.M. 2007. Bone histology and growth of the prosauropod Plateosaurus engelhardti MEYER, 1837 from the Norian bonebeds of Trossingen (Germany) and Frick (Switzerland). Special Papers in Palaeontology, 77:169-206.

Klein, N. and Sander, P.M. 2008. Ontogenetic stages in the long bone histology of sauropod dinosaurs. Paleobiology, 34(2):247-263.

Klein, N., Sander, P.M., and Suteethorn, V. 2009. Bone histology and its implications for the life history and growth of the Early Cretaceous titanosaur Phuwiangosaurus sirindhornae. Geological Society Special Publications, 315:217-228.

Klein, N., Remes, K., Gee, C. T., and Sander, P. M. 2011. Biology of the Sauropod Dinosaurs: Understanding the Life of Giants. Indiana University Press, Bloomington.

Klein, N., Sander, P.M., Stein, K., Le Loeuff, J., Carballido, J.L., and Buffetaut, E. 2012. Modified laminar bone in Ampelosaurus atacis and other titanosaurs (Sauropoda): implications for life history and physiology. PLoS ONE, 7(5):e36907.

Lamm, E.T. 2013. Preparation and sectioning of specimens, p. 55-160. In Padian, K. and Lamm, E.T. (eds.), Bone Histology of Fossil Tetrapods: Advancing Methods, Analysis, and Interpretation. University of California Press, Berkeley.

Lehman, T.M. and Woodward, H.N. 2008. Modeling growth rates for sauropod dinosaurs. Paleobiology, 34(2):264-281. https://doi.org/10.1666/0094-8373(2008)034[0264:MGRFSD]2.0.CO;2

Liston, J. 2004. A re-examination of a Middle Jurassic sauropod limb bone from the Bathonian of the Isle of Skye. Scottish Journal of Geology, 40(2):119-122.

Mannion, P. D. and Upchurch, P. 2010. Completeness metrics and the quality of the sauropodomorph fossil record through geological and historical time. Paleobiology, 36(2):283-302. https://doi.org/10.1666/09008.1

Mannion, P.D., Upchurch, P., Barnes, R.N., and Mateus, O. 2013. Osteology of the Late Jurassic Portuguese sauropod dinosaur Lusotitan atalaiensis (Macronaria) and the evolutionary history of basal titanosauriforms. Zoological Journal of the Linnean Society, 168:98-206. https://doi.org/10.1111/zoj.12029

McMahon, T.A. 1975a. Allometry and biomechanics: limb bones in adult ungulates. The American Naturalist, 109:547-563.

McMahon, T.A. $1975 \mathrm{~b}$. Using body size to understand the structural design of animals: quadrupedal locomotion. Journal of Applied Physiology, 39:619-627.

Michelis, I. 2004. Vergleichende Taphonomie des Howe Quarry (Morrison-Formation, Oberer Jura), Bighorn County, Wyoming, USA. Unpublished PhD Thesis, Universität Bonn, Bonn, Germany.

Mitchell, J. and Sander, P.M. 2014. The three-front model: a developmental explanation of long bone diaphyseal histology of Sauropoda. Biological Journal of the Linnean Society, 112:765781. https://doi.org/10.1111/bij.12324

Mitchell, J., Sander, P.M., and Stein, K. 2017. Can secondary osteons be used as ontogenetic indicators in sauropods? Extending the histological ontogenetic stages into senescence. Paleobiology, 43(2):321-342. https://doi.org/10.1017/pab.2016.47

Padian, K. and Lamm, E.T. 2013. Bone Histology of Fossil Tetrapods: Advancing Methods, Analysis, and Interpretation. University of California Press, Berkeley.

Padian, K., Werning, S., and Horner, J. R. 2016. A hypothesis of differential secondary bone formation in dinosaurs. Comptes Rendus Palevol, 15(1-2):40-48. https://doi.org/10.1016/j.crpv.2015.03.002

Ricqlès, A. de. 1968a. Quelques observations paléohistologiques sur le dinosaurien sauropode Bothriospondylus. Annales de I'Université de Madagascar, 6:157-209. 
Ricqlès, A. de. 1968b. Recherches paléohistologiques sur les os longs des tétrapodes I. Origine du tissu osseux plexiforme des dinosauriens sauropodes. Annales de Paléontologie, 54:133145.

Ricqlès, A. de. 1980. Tissue structures of dinosaur bone. Functional significance and possible relation to dinosaur physiology, p. 103-139. In Thomas, R.D.K. and Olson, E.C. (eds.), A Cold Look at the Warm-Blooded Dinosaurs. Westview Press, Boulder, Colorado.

Ricqlès, A. de. 1983. Cyclical growth in the long limb bones of a sauropod dinosaur. Acta Palaeontologica Polonica, 28:225-232.

Ricqlès, A. de, Meunier, F.J., Castanet, J., and Francillon-Vieillot, H. 1991. Comparative microstructure in bone, p. 1-78. In Hall, B.K. (ed.), Bone. Volume 3: Bone Matrix and Bone Specific Products. CRC Press, Boca Raton.

Sander, PM. 1999. Life history of the Tendaguru sauropods as inferred from long bone histology. Mitteilungen aus dem Museum für Naturkunde der Humboldt-Universität Berlin, Geowissenschaftliche Reihe, 2:103-112.

Sander, P.M. 2000. Long bone histology of the Tendaguru sauropods: implications for growth and biology. Paleobiology, 26(3):466-488. https://doi.org/10.1666/0094-8373(2000)026<0466:LHOTTS>2.0.CO;2

Sander, P.M. 2013. An evolutionary cascade model for sauropod dinosaur gigantism - overview, update and tests. PLoS ONE, 8(10):e78573.

Sander, P.M. and Tückmantel, C. 2003. Bone lamina thickness, bone apposition rates, and age estimates in sauropod humeri and femora. Paläontologische Zeitschrift, 76(1):161-172.

Sander, P.M., Klein, N., Stein, K., and Wings, O., 2011b. Sauropod bone histology and its implications for sauropod biology, p. 276-302. In Klein, N., Remes, K., Gee, C.T., and Sander, P.M. (eds.), Biology of the Sauropod Dinosaurs: Understanding the Life of Giants. Indiana University Press, Bloomington.

Sander, P.M., Mateus, O., Laven, T., and Knötschke, N. 2006. Bone histology indicates insular dwarfism in a new Late Jurassic sauropod dinosaur. Nature, 441:739-741. https://doi.org/ 10.1038/nature04633

Sander, P.M., Klein, N., Buffetaut, E., Cuny, G., Suteethorn, V., and Le Loeuff, J. 2004. Adaptive radiation in sauropod dinosaurs: bone histology indicates rapid evolution of giant body size through acceleration. Organisms, Diversity and Evolution, 4:165-173.

Sander, P.M., Christian, A., Clauss, M., Fechner, R., Gee, C.T., Griebeler, E.M., Gunga, H. C., Hummel, J., Mallison, H., Perry, S.F., Preuschoft, H., Rauhut, O.W.M., Remes, K., Tütken, T., Wings, O., and Witzel, U. 2011a. Biology of the sauropod dinosaurs: the evolution of gigantism. Biological Reviews, 86:117-155. https://doi.org/10.1111/j.1469-185X.2010.00137.x

Stein, K.W.H. and Sander, P.M. 2009. Histological core drilling: a less destructive method for studying bone histology, p. 69-80. In Brown, M.A., Kane, J.F., and Parker, W.G. (eds.), Methods in Fossil Preparation: Proceedings of the First Annual Fossil Preparation and Collections Symposium.

Stein, K.W.H., Rogers, K.C., Weishampel, D.B., Redelstorff, R., and Sander, P.M. 2010. Small body size and extreme cortical bone remodeling indicate phyletic dwarfism in Magyarosaurus dacus (Sauropoda: Titanosauria). Proceedings of the National Academy of Sciences, 107:9258-9263. https://doi.org/10.1073/pnas.1000781107

Tschopp, E., Mateus, O., and Benson, R.B.J. 2015. A specimen-level phylogenetic analysis and taxonomic revision of Diplodocidae (Dinosauris, Sauropoda). PeerJ, 3:e857.

Turner, C.E. and Peterson, F. 1999. Biostratigraphy of dinosaurs in the Upper Jurassic Morrison Formation in the Western Interior, USA. Utah Geological Survey Miscellaneous Publication, 99(1):77-114.

Waskow, K. and Sander, P.M. 2014. Growth record and histological variation in the dorsal ribs of Camarasaurus sp. (Sauropoda). Journal of Vertebrate Paleontology, 35(4):852-869. https://doi.org/10.1080/02724634.2014.840645

Wiersma, K. and Sander P.M. 2016. The dentition of a well-preserved specimen of Camarasaurus sp.: implications for function, tooth replacement, soft part reconstruction, and food intake. Paläontologische Zeitschrift, 91:145-161. https://doi.org/10.1007/s12542-016-0332-6

Woodward, H. and Lehman, T.M. 2009. Bone histology and microanatomy of Alamosaurus sanjuanensis (Sauropoda: Titanosauria) from the Maastrichtian of Big Bend National Park, Texas. Journal of Vertebrate Paleontology, 29:807-821. https://doi.org/10.1671/039.029.0310 
Woodward, H., Padian, K., and Lee, A.H. 2013. Skeletochronology, p. 195-215. In Padian, K. and Lamm, E.T. (eds.), Bone Histology in Fossil Tetrapods. Advancing Methods, Analysis, and Interpretation. University of California Press, Berkeley. 